\title{
Shared Syntax in Turkish-English Bilinguals
}

\author{
by
}

Aysegul Kutlu

A thesis submitted to the Faculty of Graduate and Postdoctoral Affairs in partial fulfillment of the requirements for the degree of

Master of Cognitive Science

in

Institute of Cognitive Science

Carleton University

Ottawa, Ontario

C 2015, Aysegul Kutlu 


\begin{abstract}
A question of interest in bilingualism research is whether each language has a unique mental representation or whether they share a mental representation. Syntactic priming studies with bilinguals suggest that structural knowledge is shared between languages. This interaction between the two languages is called "shared syntax." However, these studies have not shown the same effect for typologically dissimilar languages.

The current study aims to create an extension of syntactic priming studies by using a specific bilingual population: simultaneous interpretation students. Simultaneous interpreters are well-known for their high proficiency. Thus, interpreters are an ideal participant group to be tested in order to test the validity of the shared syntax account for typologically different languages.

This study presents different bilingual populations that have not been heavily investigated. In this respect, it will be one of the few studies that have tested the shared syntax account in Turkish with simultaneous interpretation students.
\end{abstract}




\section{Acknowledgements}

I would like to acknowledge many who directly or indirectly contributed to this thesis, and also witnessed my years of challenge. It has been a great journey thanks to all of you.

For two years, I have learned a lot from my supervisors Kumiko Murasugi and Laura Sabourin. Every week, they did not only support me intellectually, but also mentally. It has been an honour to be their student, and it will always be. I am grateful to have had that opportunity. Thank you very much for having seen the best in me, and encouraged me to find it.

I would like to thank my committee members David Wood, and our head of department Jo-Anne LeFevre who supported me for two years. Thank you very much for being in my committee.

I am thankful to my professors at Carleton University, Andrew Brook, Deepthi Kamawar, Mark MacLeod, Raj Singh and Ida Toivonen for supporting each of us with their advices. I also would like to thank my linguistics professors, who introduced me to Linguistics: Andrés Salonova, Ana Arregui, John Jensen at the University of Ottawa, and Rob Truswell at the University of Edinburgh.

Many thanks to my linguistics friends, who contributed to my linguistics life with a lot of domain-widening tools: Paul, Vesela, Nova, Ana-Sophia, Meng, Brandon, Nahed, Saleh, Pegah and Gita.

I am grateful to TÜÇEB (Turkish Translation Students' Association), and the members of EGEÇEV (Ege University Translation Students' Club), TÜÇEV (Trakya University Translation Students' Club) and ISCEV (Istanbul University Translation 
Students' Club), who voluntarily participated in this study. Without their participation, this study could not have been done.

Special thanks to my beloved friends Eralp, Aydanur, Kardelen, Nazlı, Aybüke, Fatma, Duygu, Cem, Berkay, Buse, Betül Gökçe , Seda, Murat, Musa, Funda, Elif K., Elif I., Çiğdem, Umut, Özenç, Müge, Sinem, Hazal, Kadir Boray, Soykan, Enes, and Kübra. I also would like to thank my former supervisor in Turkey, Oya Soner. Thanks to you, I was able to come to Ottawa.

I wish to thank all my ERPLings from the Brain and Language Lab at the University of Ottawa: Santa Vinerte (without your support, my life would have been miserable), Michele, Christie; thank you very much for teaching me ERPs. Many thanks to Joy, Myriam, JC, Sameer, Félix, and Ali for their academic and non-academic contributions.

I am grateful to be accompanied by amazing people: Adam Stone, Alex Olsen, Merve Babal, Tugce Boluk, Olivia Podlesny, Manon van Mil, Burcu Ünsal and Ildeniz Armutak. Without your understanding and support, my life would have been incredibly hard. Thank you very much for not only holding my hand, but also protecting me from the dark side.

I would like to acknowledge Solveiga Armoskaite and her incredible family, without whom I could not have been able to resist many problems in my life. Thank you very much for changing my life. It is thanks to you that I have achieved so many things.

I am grateful to the financial support that the Cognitive Science Department at Carleton University provided. I also would like to thank Liane, Colleen, and May from the Cognitive Science Department for all their support and help. 
I wish to thank my parents, my beautiful and small family. I am grateful to have you and your support. Thank you very much for teaching me that the only disaster that a person can have is being dishonest to oneself. Thank you for all your love and support. This thesis is dedicated to all children who will not be able to fight for money or entitlements, but for a life, a life that they can happily and peacefully live in. And last, it is all dedicated to my nephew, Ali Çakır.

Thank you very much for all... 


\section{Table of Contents}

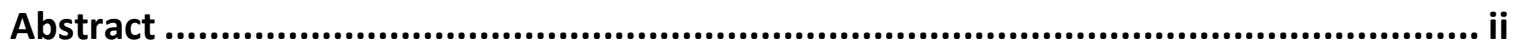

Acknowledgements ...................................................................................... ii

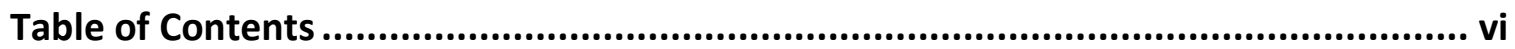

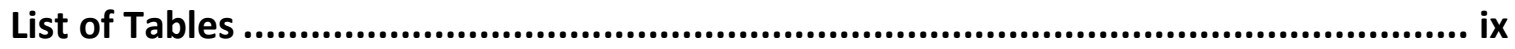

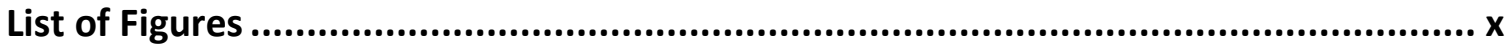

List of Appendices ......................................................................................... xi

1 Chapter: Introduction .............................................................................. 1

2 Chapter: History of Prepositional Object and Double Object Sentences................. 9

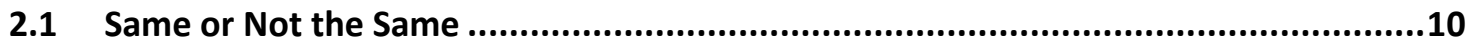

2.2 English and Turkish Prepositional Object and Double Object Sentences....................17

2.2.1 Applicative Head and Causativity Meaning in English and in Turkish ......................18

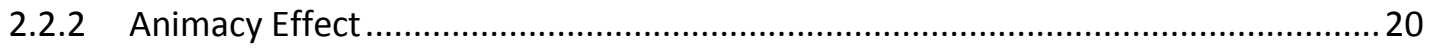

2.3 The Problem between English and Turkish Prepositional Object and Double Object

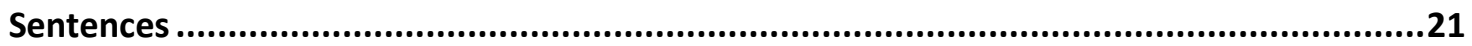

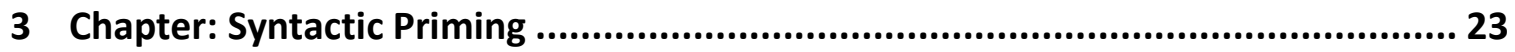

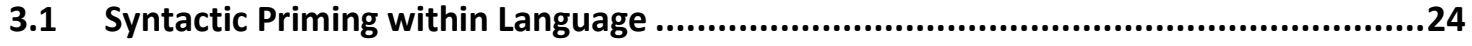

3.2 Syntactic Priming between Languages (Cross-Linguistic Priming) ............................25

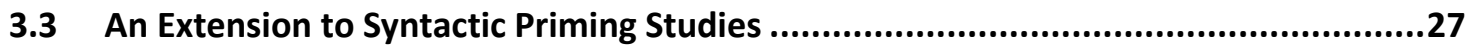


4 Chapter: Bilingualism ...................................................................................... 29

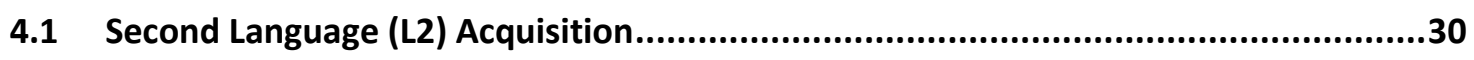

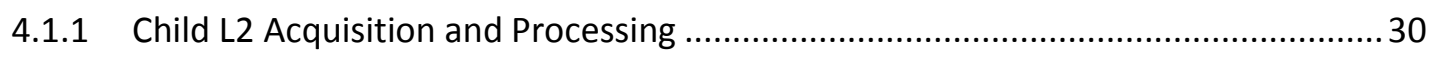

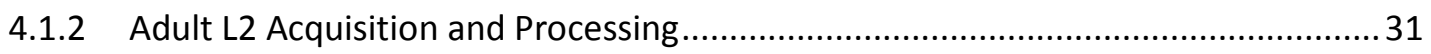

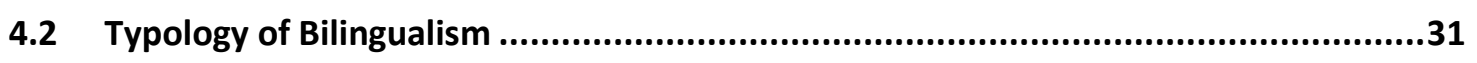

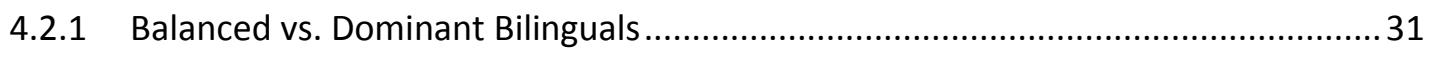

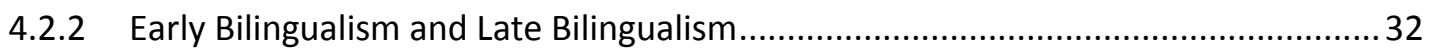

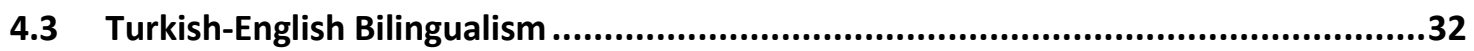

4.4 Simultaneous Interpretation as a Highly Proficient Bilingual Group .........................34

5 Chapter: Methodology ................................................................................... 37

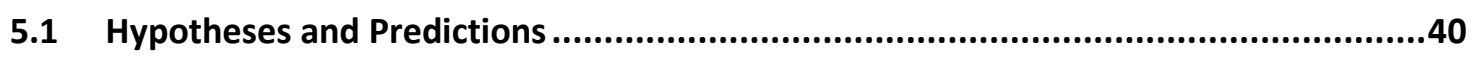

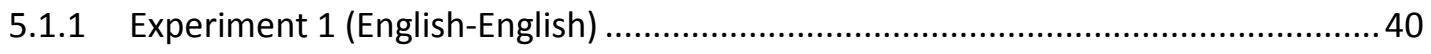

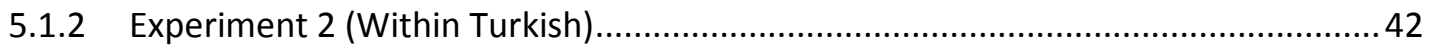

5.1.3 Experiment 3 (English-Turkish) and Experiment 4 (Turkish-English)...................... 42

5.2 Overall Experimental Design and Procedure ......................................................40

5.2.1 Recruiting and Participant Selection ............................................................ 45

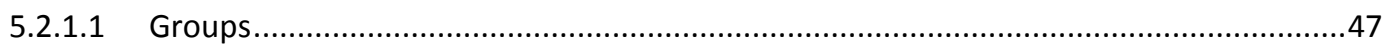

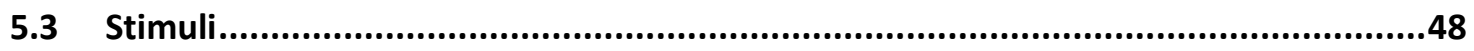

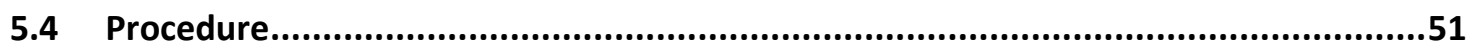

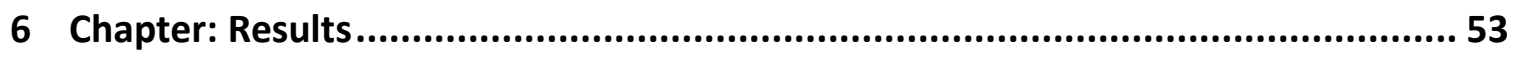

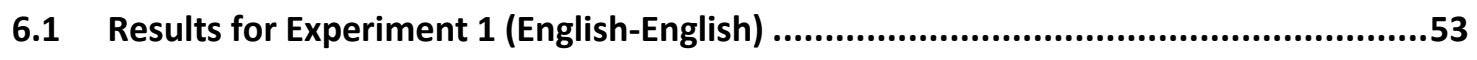

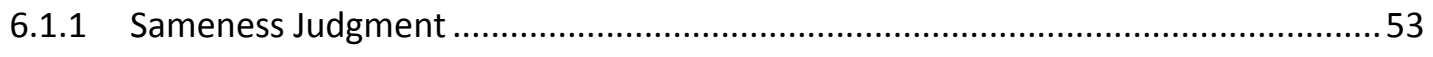

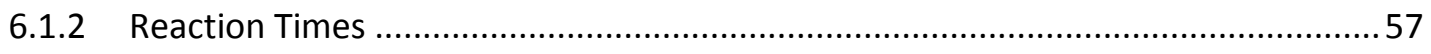

6.2 Results for Experiment 2 (Turkish-Turkish) .....................................................60 


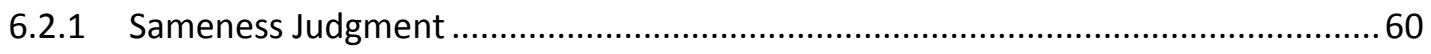

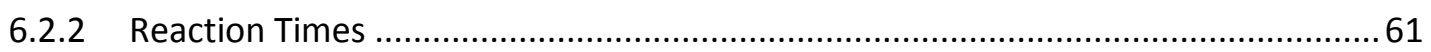

6.3 Results for Experiment 3 (English-Turkish) ...................................................62

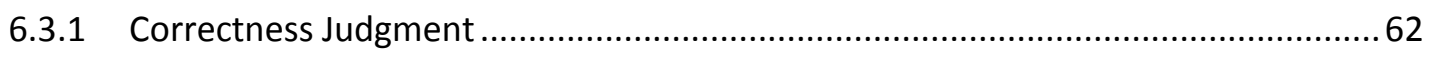

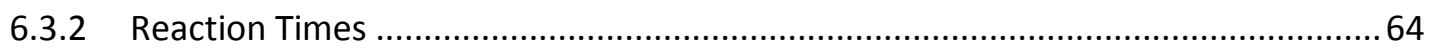

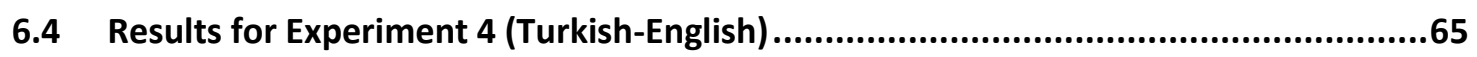

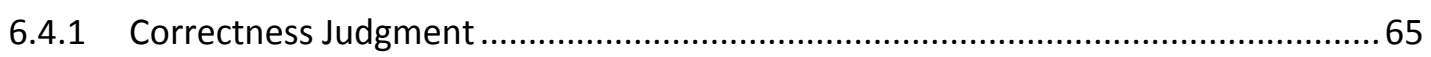

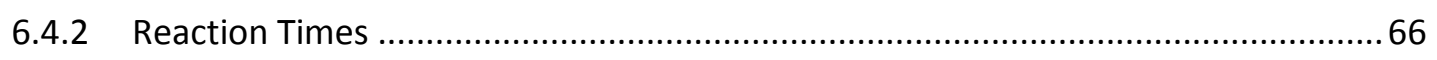

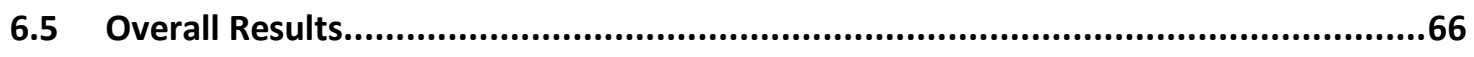

7 Chapter: Discussion and Future Directions............................................... 71

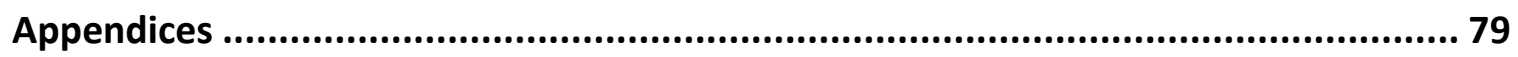

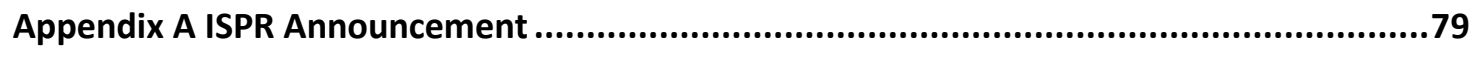

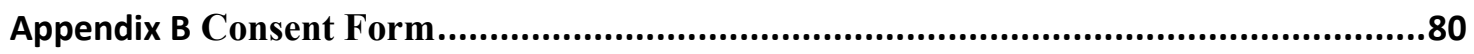

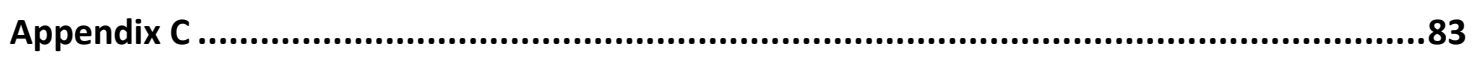

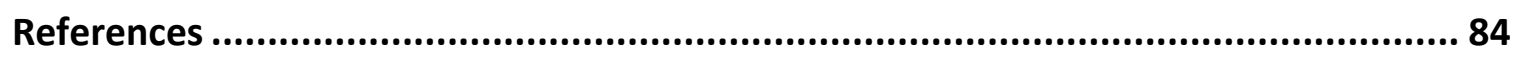




\section{List of Tables}

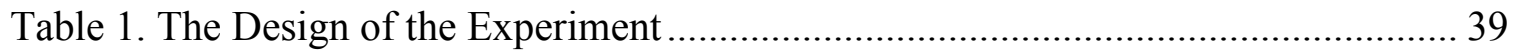

Table 2 The Distribution of Participants and Mean Age ............................................. 46

Table 3 The Distribution of the Participants by Proficiency …................................... 48

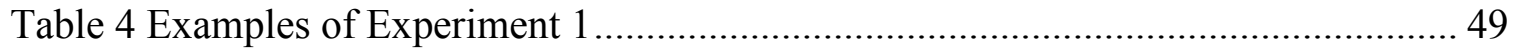

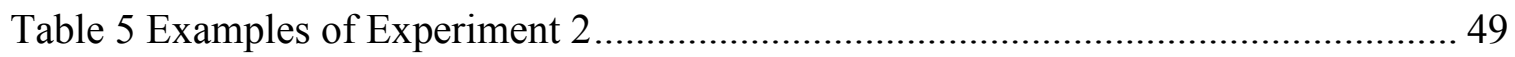

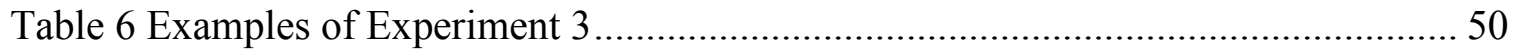

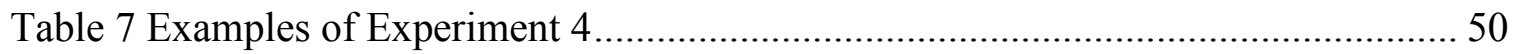




\section{List of Figures}

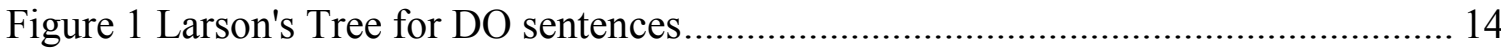

Figure 2 Larson's Tree for PO sentences ................................................................ 14

Figure 3 Sameness Judgments (\%) of all Participants in Experiment (within English) ... 57

Figure 4 Reaction Times (ms) of the Control Group ...................................................... 58

Figure 5 Reaction Times (ms) for Each Condition by Proficiency in Experiment 1 (within

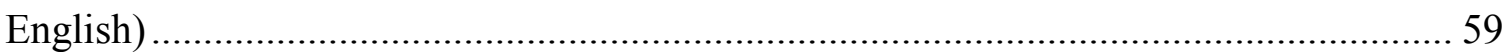

Figure 6 Sameness Judgments (\%) for Each Condition by Proficiency in Experiment 2

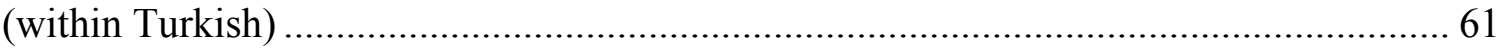

Figure 7 Reaction Times (ms) for Each Condition by Proficiency in Experiment 2 (within

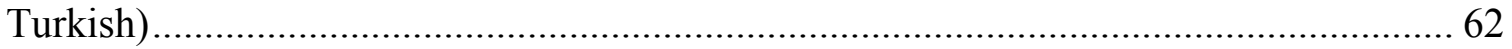

Figure 8 Correct Translation (\%) Judgments for Each Condition by Proficiency in

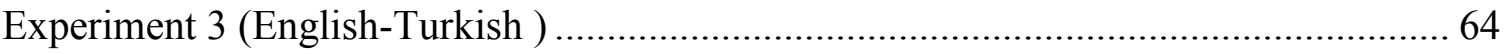

Figure 9 Reaction Times (ms) for Each Condition by Proficiency in Experiment 3

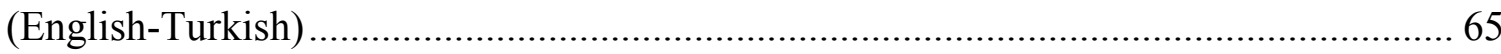




\section{List of Appendices}

Appendix A ISPR Announcement............................................... 75

Appendix B Consent Form............................................... 76

Appendix C Summary of Statistical Results........................................76 


\section{Chapter: Introduction}

What happens when we acquire another language? Do we have to create a new syntax for our new language or do we merge both of them in a shared syntax (Hartsuiker et al., 2004; Bernolet et al., 2007)? These are important questions being asked and investigated in the fields of Linguistics and Cognitive Science. In Linguistics, the answers to these questions have implications for universal grammar, a genetic endowment that makes us ready to acquire our first language, and process automatically our mother tongue in pursuit of this acquisition (Fedor et al., 2009, p. 15). Also, these questions are of interest in Psycholinguistics, mainly in second language acquisition (Flett et al., 2013).

In Cognitive Science, these questions are related to the issue of knowledge. For instance, if our first and second languages are stored separately, then they could be represented in separate knowledge systems (Ullman, 2001). This issue has been widely discussed within the modularity argument in Cognitive Science (Carruthers, 2006). If human beings have a modular mind, our language systems, including our first and second languages, are stored differently. However, the extension of modularity is still a debate in the field (Prinz, 2006). This thesis takes the language system as a modular property of the mind that interacts with other cognitive modules, so it will only focus on the language module.

The question of whether the language system is shared or separate has been investigated using different methodologies and with different populations (Bock, 1986; Branigan et al., 2000; Bernolet et al., 2007). So far the results from these studies have shown that typologically related, but not typologically dissimilar languages share syntax 
(Pickering \& Ferreira, 2007). For instance, Indo-European languages such as Dutch, German, and English share a considerable amount of grammatical information and thus it is likely they have a certain amount of shared syntax. In addition, as a sub-family, Romance languages such as French, Spanish, Italian, and Portuguese also share a considerable amount of grammatical information. Studies also show that Indo-European languages and Romance languages share a lot of grammatical information. On the other hand, languages such as Turkish and Japanese do not have these similarities when compared to Indo-European and Romance languages. One big dissimilarity between these languages and the Indo-European and Romance languages is that languages such as Turkish and Japanese are agglutinative (i.e., inflection is provided by morphemes) whereas Indo-European and Romance languages are fusional (i.e., involve conjugations of morphemes) or analytic (i.e., have no inflectional morphemes) (Poppe, 1965). Thus, these languages (e.g., Turkish and Japanese) use case-marking to mark different structures, whereas Indo-European and Romance languages have syntactic movements or structural changes. One example of this distinction comes from ditransitive verbs. These are verbs that require a theme and a goal ${ }^{1}$. In English prepositional object sentences, the theme is not marked, but the goal is marked with the preposition to (e.g., I gave the flowers to Mary). This is called a prepositional object (PO) sentence or to-dative structure $\left(\mathrm{S}-\mathrm{V}-\mathrm{O}_{1}-\mathrm{Prep}-\mathrm{O}_{2}\right)$. The double object (DO) sentence $\left(\mathrm{S}-\mathrm{V}-\mathrm{O}_{2}-\mathrm{O}_{1}\right)$ in English is not marked with a preposition, but involves a word order change (e.g., I gave Mary the flowers). Unlike English, Turkish and Japanese mark the objects of the ditransitive verbs with case markers. For instance, Turkish does not have two different structures for PO

\footnotetext{
${ }^{1}$ e.g., I brought the cookies to Myriam. "to Myriam" is the goal, "the cookies' is the theme in this sentence.
} 
and DO sentences, but it does have a word order variation for the two structures. The underlying structure for ditransitive verbs in Turkish is based on case marking. The theme is marked with an Accusative marker (-I), and the goal is marked with a Dative marker $(-E)^{2}$. Since Turkish has free word order, it allows for the scrambling of theme and dative objects (i.e., PO: S-O 1 ACC $-\mathrm{O}_{2 \mathrm{DAT}}-\mathrm{V}$; DO: $\mathrm{S}-\mathrm{O}_{2 \mathrm{DAT}}-\mathrm{O}_{1 \mathrm{ACC}}-\mathrm{V}$ ). Such similarities and differences between languages make it challenging to investigate the shared syntax account.

How bilinguals process different languages has been investigated with a syntactic (structural) priming methodology. Syntactic priming can be done both with monolinguals and bilinguals by using production tasks such as picture naming, storytelling, and sentence completion. So far, studies that have used syntactic priming have found that priming a structure in a language causes the use of the same structure in another language, which suggests that the two languages share the same syntax. For instance, Hartsuiker et al. (2004) tested English-Spanish bilinguals by using a syntactic priming methodology. In this study, participants heard a passive sentence [e.g., The boy was bitten.], and then were shown an unrelated card and were asked to describe it. When participants were primed with a structure, they tended to repeat it. This result suggested that English-Spanish bilinguals share the same passive construction for within- and crosslanguages. Syntactic priming studies with bilinguals have also focused on ditransitive verbs, specifically on PO and DO sentences (Bock, 1989).

Previous syntactic priming studies have shown that when primed with a PO or a DO sentence in one of their languages, participants produce the primed structure in their

\footnotetext{
${ }^{2}$ Note that due to vowel harmony, a phonological rule that defines which vowel comes after the previous one in Turkish, case markers (-I, -E) can change into another vowel.
} 
other language; however, this effect is only found when the two languages have the same word order (Bernolet et al., 2007). Moreover, these studies tested typologically similar languages (i.e., Dutch, German, English, Spanish) with high-proficiency bilinguals (see, for example, Pickering and Ferreira, 2008). So far, the working hypothesis of syntactic priming for the shared syntax account for PO and DO sentences has been that if two languages are typologically similar, the bilinguals of those languages can create a shared syntax (Pickering et al. 2008). Therefore, they can use their well-established first language (L1) to produce sentences in their second language (L2). For instance, if the two languages have the same structure or word order for PO and DO sentences, the bilinguals of these languages can easily process similar structures from their L1 knowledge, without storing another PO and DO structure set for their L2.

While these findings support the shared syntax account, the few studies that have been done on bilinguals of typologically dissimilar languages such as English and Japanese suggest that they do not have a shared syntax between languages (Pickering \& Ferreira, 2008). However, as indicated by Pickering and Ferreira (2008), these studies did not account for proficiency, known as the competence level acquired in the second language, when the language is acquired, known as Age of Acquisition (AoA), or how the language is acquired, known as Manner of Acquisition (MoA). Moreover, they were replicated with bilingual groups with English as a second language, with no emphasis put on the distinction between English as a second language (ESL) and English as a foreign language (EFL). For instance, in Kantola and van Gompel's (2010) experiment, SwedishEnglish participants, and in Bernolet et al.'s (2007) experiment, Dutch-English participants were tested. All participants of both studies had grown up in a bilingual 
environment; therefore, those bilingual groups were expected to comprehend and produce their L1 and L2 with automaticity (i.e., native-like proficiency) in both languages. Therefore, proficiency and MoA played a major role in previous studies. However, it is still not clear whether the shared syntax occurred due to high proficiency or due to typological similarities.

This study aims to expand the shared syntax account from a different point of view. While most studies tested typologically similar languages with high proficiency L2 speakers, the present study tested bilinguals of typologically different languages (i.e. Turkish-English) on PO and DO sentence processing. These Turkish-English bilinguals were simultaneous interpreting students, who were taught English as a foreign language until the university level, and who had English as a second language at the university level ${ }^{3}$. A specific bilingual group speaking typologically different languages was chosen for two reasons: to cancel the typological similarity effect and to strengthen the proficiency effect, in order to understand the underlying structure of the shared syntax account.

In many countries where the general population is monolingual, it is possible to learn English as a second language--although it is taught as a foreign language. In Turkey, the general population is comprised of Turkish monolinguals, but the education system has English as a foreign language. Completing English as a foreign language is necessary to obtain a high school degree. If one would like to further their education in English, there are universities that teach English as a second language, and there are programs in which English is the only language of education. Students who want to

\footnotetext{
${ }^{3}$ Since English is not the official language of the Rebuplic of Turkey, in this context ESL means having an advantage of learning English from native speakers and having maximum exposure to English.
} 
attend these programs have to successfully pass an English test (e.g. TOEFL, IETLS, Foreign Language Examination in Turkey). The programs that require more than 90 percentile of success in English tests are translation and interpreting programs.

Simultaneous (conference) interpreting is a cognitively demanding task in which the interpreter must process two languages at the same time. The interpreter must comprehend and store in memory new speech input that is presented continuously. Earlier input must be reformulated mentally into the target language and then be articulated quickly and concisely (Gerver, 1976; Lambert, 1992; Ruiz, Paredes, Macizo, \& Bajo, 2008). Given the demands of simultaneous interpreting, the task would be more efficient if interpreters accessed just one linguistic system (i.e. a shared syntax) that represented both languages. Hypothetically, in a monolingual environment (e.g. Turkey), simultaneous interpreters represent the high proficiency bilingual group, even though they start their training as low proficiency bilinguals because they are taught English as a foreign language throughout their education until university.

Empirically, simultaneous interpreters have been shown to use syntactic priming as a strategy during interpretation (De Bot, 1992). De Bot (1992) showed that simultaneous interpreters (Dutch-French) used a prepositional object for a French verb when it required a double object. This demonstrated a priming effect of Dutch double object over French prepositional object when they were interpreting from Dutch to French. In simultaneous interpretation, borrowings as such were common. Therefore, simultaneous interpreters seemed to show a priming effect, meaning they rely on structures and tend to repeat the same structure, if applicable, in the target language. If it is not applicable, they still tend to use the same structure because of the priming effect. 
This strategy may play a role in creating a shared syntax between languages, no matter how typologically different they are. On the other hand, it might be the case that simultaneous interpreters become highly proficient due to their intense training in languages, and have native-like ability to use different structures both in the target and source languages. Or they apply in the target language, the structures that are not available in the source language. As a result, a shared syntax can be created. While typological similarity and proficiency may lead to the shared syntax account, this sharing process still needs to be investigated in terms of underlying representations. For instance, if simultaneous interpreters are able to look beyond typological differences, they are behaving similarly to other high proficiency bilingual groups of typologically similar languages. Thus, by analyzing different bilingual populations such as simultaneous interpreting students, one could expand the shared syntax account for typologically different languages, and investigate the effect of proficiency on typological similarity. In this regard, shared syntax in this study means a total of linguistic and cognitive information that can be shared between languages, which may or may not appear on the surface level. For instance, typologically similar languages have a shared syntax in terms of grammatical information, and it is easier to investigate these similarities (e.g., syntactic priming) (Pickering et al., 2008). However, typologically dissimilar languages have different grammatical information, but many aspects of the linguistic components may have been hidden under or merged with the cognitive mechanisms. One example of this is animacy. Animacy plays a role both in linguistics and in cognition (Verhoeven, 2012). Another examples are number and definiteness (Frank, 2008). These effects in typologically different languages may provide us with 
information about shared syntax. Although, it is not necessary to have similar syntax cross-linguistically, shared information in syntax such as animacy can play a role in shared syntax in typologically different bilinguals.

Moreover, an empirical investigation of $\mathrm{PO}$ and $\mathrm{DO}$ sentences can provide more information for future research in terms of the theoretical base of PO and DO sentences (i.e., are they derivational cross-linguistically?). Thus, the aim of this study is to investigate the processing of $\mathrm{PO}$ and $\mathrm{DO}$ sentences between English and Turkish, and to analyze whether the typology advantage disappears and a shared syntax is created when bilinguals reach a certain level of proficiency.

Chapter 2 of this thesis will begin with a presentation of the shared syntax account and it will present the historical evaluation of prepositional (PO) and double object (DO) sentences, and why they are of interest to this thesis. Chapter 3 will present the syntactic priming studies, and how these studies have tested the shared syntax account. Chapter 4 will present bilingualism and how different bilingual groups can be tested. Chapter 5 will present and discuss the research questions and the methodology. Chapter 6 will present the results of the experiments. Chapter 7 will discuss the implications of these results and present future directions of research. 


\section{Chapter: History of Prepositional Object and Double Object}

\section{Sentences}

A question of interest in Psycholinguistics is whether bilingual speakers comprehend and produce sentences by using a shared syntax or a separate syntax for each language. Recent research has asked this question. While some studies suggest the shared syntax account (Bernolet et. al, 2007; Pickering, 2007;), others suggest the separate syntax account (Meijer \& Fox Tree, 2003; Hartsuiker et al., 2004).

Until now, structures such as active/passive, relative clause, complex noun phrases, and PO/DO sentences have been tested in accounts supporting the shared syntax approach. Many of these studies were done by using a structural priming technique (see Chapter 4). It is important to note that although structural priming has been heavily used to investigate the shared syntax account for different languages, so far the languages that have been tested belong only to the Indo-European and Romance language families.

The main hypothesis of the shared syntax account is that if two languages are typologically related, and especially if they have the same word order, bilinguals of these languages share information for the two languages. Therefore, for those bilinguals, comprehension and production are both fast and accurate.

On the other hand, there have been few studies on typologically different languages. The studies that do exist have failed to show a shared syntax for typologically different languages (Hartsuiker et al., 2004; Pickering \& Ferreira, 2008). One of the reasons for this has been word order variance. 
Structurally variable sentence types between distinct languages are prepositional (PO) and double object (DO) sentences cross-linguistically. In the next chapter I will discuss the typology of these sentences.

Recent studies in Psycholinguistics suggest that children rely on structural information instead of semantic information (Felser, Marinis \& Clahsen, 2003; Traxler, 2002; Trueswell, Sekerina, Hill \& Logrip, 1999), while adult L1 or L2 speakers rely on semantic information or so-called world knowledge to process a sentence rather than syntactic information (Felser, Roberts, Gross \& Marinis, 2003; Papadopoulou \& Clahsen, 2003). However, many of these studies were done with syntactic ambiguities, where semantic information — world knowledge — was a key point for the participants processing the sentences (e.g., semantic ambiguity in relative clause structures). However, prepositional (PO) and double object (DO) sentences, which have sometimes been considered syntactically distinct, semantically similar or syntactically and semantically similar, represent the distinct point of views on the syntax-semantics interface.

\subsection{Same or Not the Same}

The distinction between PO and DO sentences has been shown in many theoretical works (Chomksy, 1955, 1977; Oehrle, 1976; Larson, 1988; Pinker, 1989; Bresnan et al., 2007; Bruening, 2010; Miyagawa \& Tsujioka, 2012). What makes PO and DO sentences syntactically different but semantically the same is that both structures are available for many ditransitive ${ }^{4}$ verbs. For instance, in English, sentences (1) and (2) are

\footnotetext{
${ }^{4}$ Ditransitive verbs take a subject and two objects (e.g., give, send, bring)
} 
both available for PO and DO structures, but while sentence (3) is available for PO structure, it does not allow DO structure (4):

1. Noam gave a paper to Bill.

2. Noam gave Bill a paper.

3. Noam introduced Bill to Mary.

4. *Noam introduced Mary Bill.
PO structure

DO structure

PO structure

DO structure

Similarly, in French, the preposition "à" is the default marker of PO structure, and when DO structure is applied, the indirect object is indicated by a moved pronoun (e.g., lui), such as in sentences (5) and (6).

5. Noam a donné une papier à Bill. PO structure Noam AUX gave one paper to Bill 'Noam gave the paper to Bill.'

6. Noam lui a donné une papier. DO structure Noam him AUX gave one paper 'Noam gave him the paper.'

Recall that Bill has to move up as a pronoun 'lui' because French does not allow proper nouns to move upwards, making the following sentence ungrammatical:

7. *Noam Bill a donné une papier. DO structure Noam Bill AUX gave one paper 'Noam gave Bill the paper.'

A closer look at the sentences (5) and (6) also shows that in English and French, DO structures are not used without a reference point. For instance, imagine that two speakers are talking about Noam's giving [a donné] action. However, both speakers know that Noam gave a paper to both Bill and Martin. In this case, if one of the speakers chooses sentence (6), the other speaker cannot understand the reference point since 'lui' may 
entail either Bill or Martin. Therefore, speakers may be confused or may find DO structures without a reference point unacceptable.

Other languages mark or represent PO and DO sentences differently. For instance, while agglutinative languages such as Turkish, Korean, Finnish and Japanese mark direct and indirect objects with different case markers, synthetic and isolating languages (i.e., English, French, German, Greek, Italian, Spanish) have different structures, such as prepositional phrases.

There has been no consensus on the syntax of the PO and DO sentences in English because of the cross-linguistic variability. While some claim that one of the structures is derived from another, others claim that both structures are the same, and some others claim that the two structures are completely different. I will briefly summarize the different points on the syntax of PO and DO sentences historically.

In his earlier work $(1955,1975)$, Chomsky pointed out that sentences such as (8) and (9) have to undergo transformation. From this view, the underlying structure is a DO (8), and then undergoes a transformation ${ }^{5}$ to become a PO (9). According to Chomksy, ditransitive verbs such as 'give' and 'send' create a VP constituent with the Goal prepositional phrase. The $\mathrm{V}$ then raises and a PO structure is realised. For instance, the underlying structure of (9) is (8).

8. Noam [vp his objections [v sent to the students]]

9. Noam sent [vp his objections [v $t$ to the students]]

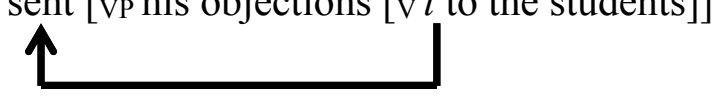

\footnotetext{
${ }^{5}$ This transformation is called V Raising. V Raising is simply an upward movement of the predicate of a sentence to the subject position of the embedded predicate.
} 
Dryer (1986) proposed that the DO structure is the basic sentence, and PO sentence is a derivation of the DO structure. Dryer used Active and Passive voice sentences to show the underlying structures for PO and DO sentences.

10. Mary gave a book to John. PO Active

11. Mary gave John a book. DO Active

12. A book was given to John by Mary. $\quad$ PO Passive

13. John was given a book by Mary. $\quad$ DO Passive

When the previous examples are compared, it is easy to see that all the sentences have the same meaning. The only difference is that sentences (10) and (11) are in the active voice, whereas sentences (12) and (13) are in the passive form. When we look at the following sentences, we see a different case for PO sentences because there are some PO sentences that can be beneficiary (for someone) rather than a recipient (to someone):

14. Mary bought a book for John. PO Active

15. Mary bought John a book. DO Active

16. *John was bought a book by Mary. $\quad$ PO Passive

17. A book was bought for John by Mary. DO Passive

Although sentences (14) and (15) are examples of PO and DO sentences, they are not identical to sentences (10) and (11) because examples (14) and (15) have the preposition for. Moreover, sentence (16), the passive form of sentence (14), is ungrammatical.

Larson (1988) claimed that the relation between DO and PO structures is similar to the way in which actives and passives are related. In contrast to Chomsky and Dryer, Larson proposed that DO structures are derived from PO structures (see Figure 1a) 
through the operation of dative shift. Dative shift involves processes similar to those found in the passive construction (see Figure 1): the withdrawal of dative Case to the object of the preposition to (e.g. Mary in the PP to Mary), the movement of the caseless object Mary to subject position (Spec of the lower VP in Figure 2), and the realization of PO sentence.

Figure 1 Larson's Tree for DO sentences

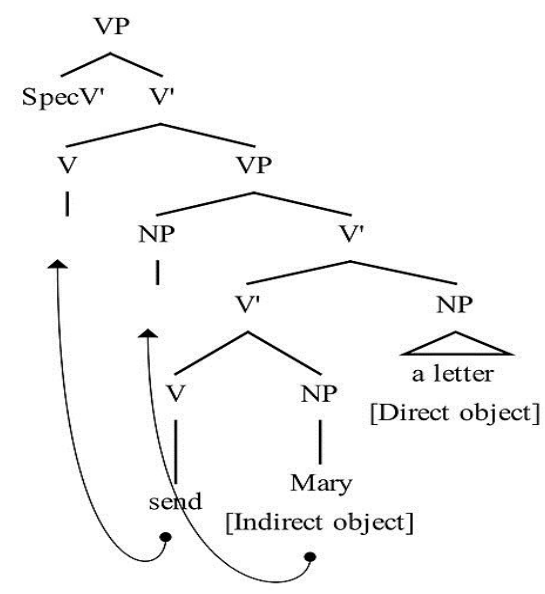

Figure 2 Larson's Tree for PO sentences

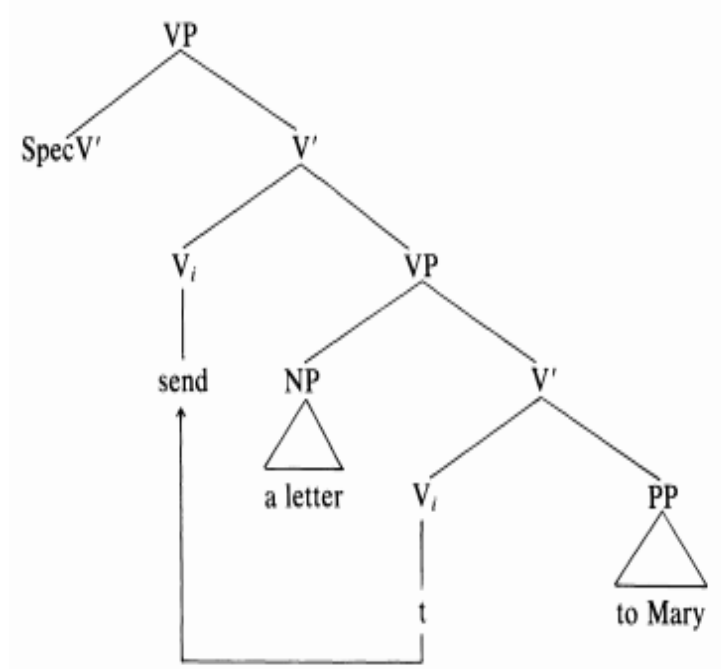


Bruening (2001) proposed that PO and DO structures are distinct sentences because DO sentences have an extra grammatical component called an applicative head, which can be morphologically null. An applicative head is a grammatical component that raises the indirect object to the direct object position. This head is mainly applied to causative and passive sentences in English (Bruening, 2001). For instance, the following sentence (18) with a DO structure is grammatical but sentence (19) is not grammatical.

18. The article gave me a headache.

19.*The article gave a headache to me.

The previous example shows that DO structures have a distinct usage from PO structures. This distinct usage is causativity because the verb 'to give' has a causative meaning in that the article caused me to have a headache. This causative meaning occurs because the applicative head in DO structures allows the movement of the pronoun 'me' next to the verb 'give'. This distinct usage is not available for PO structures. This unavailability suggests that PO and DO sentences have distinct structures and semantics (Bruening, 2001).

However Bresnan et al. (2007) opposed this view. They claimed that PO and DO structures are syntactically identical, and speakers can choose one or the other, depending on various factors such as animacy and definiteness. They also argued that speakers have substantial knowledge of what they are going to say during an utterance, and it is their choice to pick one structure to convey their message. In their analysis, Bresnan et al. showed examples that were against Bruening's view. They concluded that speakers actually prefer to use PO with causative sentences. The following sentence (20) is an example of this case: 
(20)... a stench or smell is diffused over the ship that would give a headache to the most athletic constitution.

Bruening (2010) argued against Bresnan et al.'s view. His account suggests that Bresnan et al.'s examples are not DO sentences. They are actually PO sentences that have undergone another shift called R-dative shift ${ }^{6}$.

According to Miyagawa and Tsujioka (2012), PO and DO sentences are different in terms of the nature of the goal phrase (p. 65). By referring to Bresnan (1978, 1982b), they indicated that the goal phrase in a DO sentence is more restricted in terms of animacy than a PO sentence. The following sentences are taken from Miyagawa and Tsujioka (2012):

21. I sent the boarder / *the border a package.

22. I sent a package to the boarder / the border

While sentence (21) is grammatical with an animate object [the boarder], it is not grammatical with an inanimate object [the border], whereas sentence (22) allows for both animate and inanimate objects.

The aim of this subsection was to show the historical evaluation of PO and DO sentences in English. In the next section I will clarify the differences between PO and DO

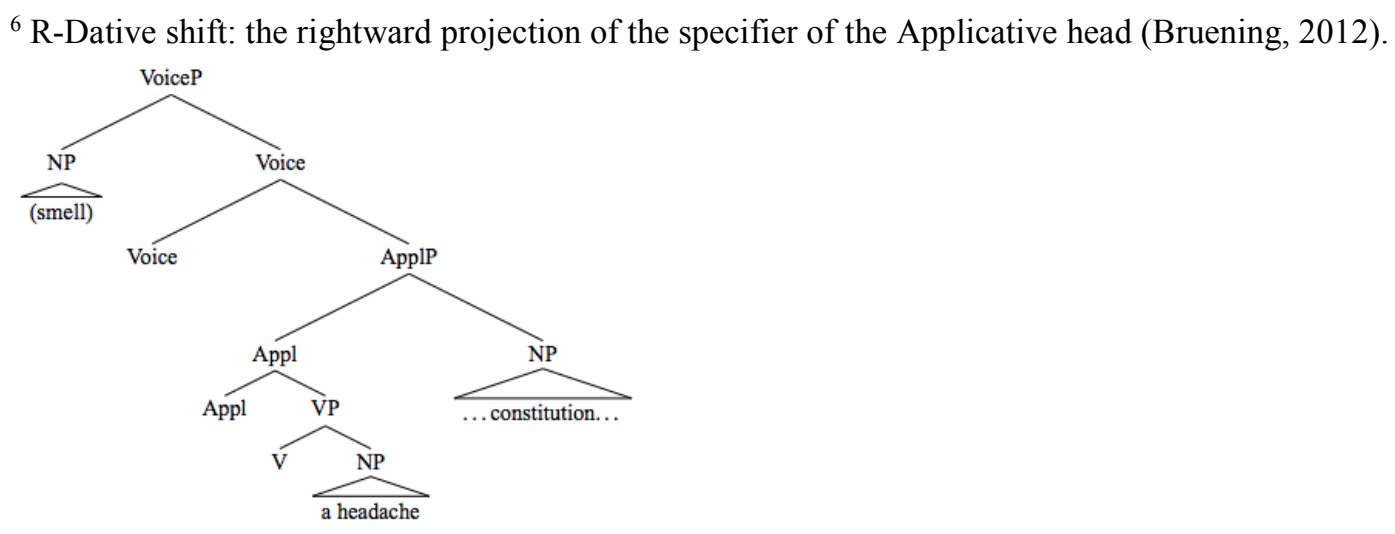


structures in English and in Turkish, and explain how PO and DO sentences were used in this experiment.

\subsection{English and Turkish Prepositional Object and Double Object Sentences}

As shown in the previous section, there is no consensus on the syntax of PO and DO structures in English. While the underlying structures of PO and DO sentences have been heavily investigated in English, the cross-linguistic variances of such structures have not been observed in detail. In the following subsection, I will summarize how English PO and DO sentences have been discussed, and will apply the same discussion to Turkish. The following subsections will also show how the sentences in the experiment were designed.

PO and DO sentences are structurally and semantically different in English (i.e., causativity reading only occurs in DO sentences, PO sentences are not sensitive to inanimate indirect objects but DO sentences are sensitive to them). However, under certain conditions, some ditransitive verbs such as 'give' and 'send' have two structures in English: (23) PO structure, (24) DO structure ${ }^{7}$. For instance, both of the following sentences have the same meaning (i.e., one semantic reading), but they have two different structures.

23. John gave the flowers to Mary. $\quad P O$ structure

24. John gave Mary the flowers. DO structure

As I summarized in the previous section, there is no agreement on whether the PO structure is derived from the DO or vice versa. The most recent theoretical view on this issue is that neither PO nor DO is derived from one another, at least in English, but that

\footnotetext{
${ }^{7}$ Theoretically, PO structures are also called to-dative structures. For the sake of clarity, in this thesis, I will use the term 'PO'.
} 
they are two distinct structures (Marantz, 1993; Goldberg, 1995; Harley, 1995; Bruening, 2001; Pylkkänen, 2002; Beck \& Johnson, 2004). The pieces of evidence for that conclusion are the causativity reading and animacy. However, when one looks at Turkish, we do not see the same evidence of distinct structures, but instead word order variations due to the highly marked case system in this language. Thus, in Turkish, there is one structure, with direct objects marked with Accusative case (ACC) and indirect object with Dative case (DAT). The PO and DO word order only appears by changing the two ACC and DAT arguments: PO: Agent ${ }_{\mathrm{NOM}}-$ Theme $_{\text {ACC-Goal }}$ DAT $_{\text {and }}$ DO:Agent NOM$^{-}$ Goal $_{\text {DAT-Theme }}$ ACC. The same phenomenon happens in Japanese as well (Miyagawa, 2004). The following examples show the PO and DO word order in Turkish.

25. Ali çiceğ-i Ayşe-ye verdi. PO word order Ali flower-ACc Ayşe-DAT gave 'Ali gave the flower to Ayşe.'

26. Ali Ayşe-ye çiceğ-i verdi. DO word order Ali Ayşe-Dat flower-acc gave 'Ali gave Ayşe the flower.'

PO and DO structures in Turkish have not received as much attention as their English equivalents because they involve only a change in word order. In the following subsection, I will explain each factor that has been proposed for English PO and DO distinctions and compare them to their Turkish equivalents.

\subsubsection{Applicative Head and Causativity Meaning in English and in Turkish}

As discussed earlier, DO structures have an applicative head which gives a causative meaning to the sentence. To test whether Turkish DO word order also has a causativity reading, the following sentences will be compared to their equivalents in 
Turkish. We will see that the causativity effect only applies to English DO structures, because in Turkish, causativity is provided by the verb 'yapmak' [to make]. The following sentence (27a) is the equivalent of sentence (27b), and (27b) is ungrammatical. Sentence (27c) is the equivalent of sentence (27a). However, sentence (27b) and sentence (27c) do not have the same structures and same lexical items, such that in English, the verb 'to give' - a ditransitive verb - is used while in Turkish the verb 'to make'-an intransitive verb- is used.

a) The article gave me a headache.
b) *Makale bana baş ağr1-s1 ver-di. Article me head pain-POSS3SG give-PAST3SG (Intended: The article gave me a headache.)
c) Makale baş ağrı-s1 yap-tı. Article head pain-POSS3SG make-PAST3SG (Literal translation: 'The article made me a headache.' Intended meaning: 'The article gave me a headache.')

The comparisons of English and Turkish DO structures in terms of causativity have shown that causativity only applies to English DO structures.

Overall, English PO and DO sentences have been seen syntactically and semantically different for some cases such as causativity. However, the causativity does not hold cross-linguistically as it does not apply to Turkish ditransitive verbs. This shows that Turkish does not have two distinct structures (PO or DO) for ditransitive verbs but one structure (ACC and DAT case marking). Because the causativity reading does not hold in Turkish, DO and PO structures with causative meaning in English will not be discussed further in this thesis. 


\subsubsection{Animacy Effect}

Animacy is a syntactic and semantic component that indicates whether a noun is animate or inanimate. In English PO and DO sentences, animacy plays an important role. If we compare sentences (28a) and (28b) to their equivalents in Turkish, we see that there is no animacy effect; that is, both PO and DO word order are fine with inanimate goals. Therefore, a free variation of both PO and DO word order can occur in sentences with goal phrases (see (28c) and (28d)) in Turkish.

a) I sent the boarder / *the border a package.

b) I sent a package to the boarder / the border

c) Ben pansiyoner-e / sınır-a paket-i gönder-di-m. I boarder-DAT/ border-DAT package-ACC send-PAST-1SG 'I sent the boarder/the border a package.'

d) Ben paket-i pansiyoner-e / sinır-a gönder-di-m. I package-ACC boarder-DAT/ border-DAT send-PAST-1SG 'I sent a package to the boarder / the border.'

As examples (28c) and (28d) show, animacy does not play a role in goal phrase structures in Turkish as neither sentence (28c) nor sentence (28d) shows an animacy effect with regards to DO and PO structures. ${ }^{8}$ This again can be evidence that Turkish does have one structure for ditransitive verbs; therefore it does not have two distinct structures.

\footnotetext{
${ }^{8}$ Please note that sentence (c) has DO order and sentence (d) has PO order.
} 


\subsection{The Problem between English and Turkish Prepositional Object and Double Object Sentences}

The syntactic differences between PO and DO sentences are clear: DO sentences have an extra applicative head, and therefore they can imply causativity under some circumstances (Bruening, 2001). Moreover, DO sentences are sensitive to animacy. However, PO sentences show sensitivity to neither causativity nor animacy. The challenge is reconciling that for some ditransitive verbs in English, such as 'to give' and 'to send,' both PO and DO structures are available - and they mean exactly the same thing.

On the other hand, Turkish, an agglutinative language, does not seem to have this problem, because it marks first and second objects with different case markers. However, Turkish allows for word order changes between the theme and goal. Thus, both themegoal and goal-theme object variations are possible in Turkish. One language (English) has two structures for some ditransitive verbs; the other (Turkish) has one structure but two word orders for all ditransitive verbs. Although we do not know whether English native speakers prefer one structure over the other, we know that PO and DO word orders can be related to focus in Turkish, and the same may hold for English native speakers. For instance, if John regrets that he gave the flowers to Mary instead of to Jane, he will most likely utter 'I gave the flowers to MARY'. However, if John regrets that he gave flowers, but not chocolate, to Mary, he will most likely utter 'I gave Mary the CHOCOLATE'. This change in focus can be investigated with prosody. In addition, we know that if a Turkish speaker would like to make a pragmatic change (i.e., emphasizing the goal (e.g., Mary) instead of the theme (the flowers)), they would put the goal right 
before the verb, because the object that comes right before the verb is focused in Turkish (Cetinoglu \& Butt, 2008). However, as the scope of this thesis is to investigate the shared syntax account, the effects of prosody on syntax will not be discussed here.

If Turkish does allow for word order variations for PO and DO sentences, and some ditransitive verbs in English allow for both PO and DO sentences with a possible difference in focus, how are these types of sentences processed in bilingual brains? If the differences between PO and DO are too sporadic to be identified, how could this affect the shared syntax account? Or do Turkish speakers have a preference for PO or DO word orders with regards to animacy? As I indicated before, one way to test the shared syntax account is to use structural (syntactic) priming. In the next chapter I will discuss structural priming studies and how this study differs from them. 


\section{Chapter: Syntactic Priming}

Studies show that in everyday dialogues, speakers tend to repeat their own structures or others' structural choices. This repetition is not considered a product of working memory, but is considered a reflection of natural language processing (Pickering \& Ferreira, 2008).

Repetition is the central point of many behavioural studies, as it reflects the underlying structure of many different operations, such as knowledge storage and information processing (Pickering \& Ferreira, 2008). Recently, studies in Neuroscience have shown that repetition is also related to mirror neurons, one of Neuroscience's most important discoveries to date. Mirror neurons are known as the imitating cells in human brain that are believed to play a role in language acquisition, and other forms of imitative behavioural learning (Lingnau \& Caramazza, 2014).

In Psycholinguistics, this repetition effect is known as priming ${ }^{9}$. As Pickering and Ferreira (2008) indicated, repetition (priming) might reflect three things: learning and development capability (when we acquire a capability, we start to repeat the outcomes of this capability), imitation (repeating or imitating others' behaviour to achieve communication), and executive control (inability to inhibit a previous and potential response).

Syntactic (structural) priming is a recent methodology, investigating the repetition effect in natural language processing. If priming occurs, it shows that the primed structure is shared cross-linguistically and it affects the target structure.

\footnotetext{
${ }^{9}$ Exposure to a stimulus influences response to the next stimulus.
} 
Syntactic (structural) priming has been used in various languages by using different structures such as object orders and locative case (Hartsuiker, Kolk \& Huiskamp, 1999). The order of verb and auxiliary is another environment where it occurs (Hartsuiker \& Westenberg, 2000). Lastly, it occurs in complex noun phrases (Cleland \& Pickering, 2003). These different studies were done on languages such as English, Spanish, German, Dutch, Greek, and French, which are all typologically similar. For the purpose of the current paper I will discuss syntactic priming of two types: (i) within language and (ii) between languages.

\subsection{Syntactic Priming within Language}

Levelt and Kelter (1982) created a structural priming task to investigate processing in Dutch. In one experiment, they asked Dutch shopkeepers one of the following questions:

1. Om hoe laat gaat uw winkel dicht? (At what time does your shop close?)

2. Hoe laat gaat uw winkel dicht? (What time does your shop close?)

The answer for the first one was: Om viif uur. (At five o'clock). The answer for the second one was: Viif uur (Five o'clock). As one could see from this paradigm, Dutch shopkeepers tended to preserve the structure of the questions, by using a preposition (“At...") or a nominal phrase ("Five..."). This showed that the structure of the questions primed the answers in Dutch. This study was followed up by Bock (1986). Bock used syntactic priming to test English speakers' transitive verb processing in either active or passive form, and their dative sentence processing in either a prepositional-object or double-object sentence. In that experiment, Bock asked them to explain a picture. This 
study showed that the speakers were more likely to repeat the structure with which they were primed; this allowed others to claim structural alignment.

However, for bilingual sentence processing, syntactic priming studies are mostly done to investigate the shared syntax account. If one structure in language $\mathrm{X}$ primes a similar structure in language $\mathrm{Y}$ then it could be interpreted as the sharing of syntax. This suggests that bilinguals can share syntax if there is a typological or word order similarity.

\subsection{Syntactic Priming between Languages (Cross-Linguistic Priming)}

Bock (1986) showed that similar surface structures in two languages are evidence for structural priming cross-linguistically. For instance, Pickering and Ferreira (2008) assumed that, due to similarities between Spanish and English passive constructions, Spanish-English bilinguals might share the same structure for the passive. For example, a Spanish-English bilingual knows that both languages have a passive construction, but may only have one store of knowledge underlying the passive structure, which they use this store to produce passive sentences in English and in Spanish (e.g. a and b).

a. The truck is chased by the taxi.

b. El camión es perseguido por el taxi.

Sentences (a) and (b) ${ }^{10}$ have the same word order, and the surface structures in both languages are similar. Thus, Spanish speakers might preserve the passive structure when they are primed with an English passive sentence.

However, there is some counter evidence to this analysis. Bernolet et al. (2007) found priming with complex noun phrases (e.g., the sheep that is red) by testing DutchEnglish bilinguals. They first found a priming effect within Dutch (L1), and then within

\footnotetext{
${ }^{10}$ Sentence (b) is the verbatim equivalent of sentence (a).
} 
English (L2), but no cross-linguistic priming in either direction. They concluded that this lack of priming might have happened because Dutch reverses the order of the verb and adjective (Dutch: the sheep that red is...). Further, they did the same study by testing Dutch and German, two languages that have the same word order, and they found priming from German to Dutch.

The reason for this lack of priming arises from cross-linguistic word order differences. In both Dutch and German, the adjective is placed between the relative pronoun and the verb of the relative clause (e.g., the sheep that red is...). In English, the adjective is placed at the end of the relative clause (e.g., the sheep that is red...). Therefore, while Dutch and German have the same word order for adjectival noun phrases, Dutch and English do not share word order for noun phrases that use relative clause structures.

Pickering and Ferreira (2008) hypothesised that bilinguals share as much grammatical information as they can, given the extent to which grammatical differences within a language are represented together (p. 452).

Although typologically similar languages have been tested using syntactic priming, the effect of word-order differences has not been fully defined yet. As in Bernolet et al.'s (2007) study, languages that share the same word order for specific structures show that they are affected by priming, but if they do not share the same word order they do not show a priming effect. However, it is crucial to investigate whether the priming effect is directly related to or is derived from the word order similarities or high proficiency. Thus, future studies would benefit from investigating syntactic priming in different bilingual populations to investigate the shared syntax account. 
As mentioned above, syntactic priming studies have primarily focused on production-based tasks; this makes it easy to test highly proficient bilinguals. However, a comprehension task would be the most useful to investigate the effects of syntactic priming on different bilingual populations. In the next subsection, I will briefly summarize the sameness judgement task.

\subsection{An Extension to Syntactic Priming Studies}

Structural priming studies with typologically related languages have created a cogent case for the shared syntax account; however, cross-language structural priming has failed to have a priming effect in typologically different languages. Pickering and Ferreira (2008) argue that it is unlikely that typologically different languages share structures.

In this study, I will argue that a slight change in the design of structural priming experiments can lead to different results. Production focused structural priming tasks may not be the only way to show shared syntax.

The idea behind structural priming studies is to use production-based data (i.e., describing cards or pictures, storytelling) instead of comprehension-based tasks (i.e.,

judgments). Structural priming studies offer behavioural data for typologically different languages, but the underlying neurophysiological differences are not known because the analysis is limited to production tasks. Merging comprehension data with production data, which is less problematic on many fronts than production data, is another way to have more information about bilingual language processing, because of the importance of the shared syntax account in bilingual sentence processing. 
This study will demonstrate a new way to test the shared syntax account by using comprehension data. In previous structural priming studies, participants are primed with a type of sentence, and then they are asked either to describe a picture or a card or to narrate a story. In the present study, participants are asked to do sameness judgement and correct translation judgement tasks. The design of these tasks will be presented in the Methodology chapter. 


\section{Chapter: Bilingualism}

As indicated in the previous chapters, this study aims to investigate the bilinguals of typologically dissimilar languages. In order to do this, a clear description of bilingualism, and the bilingual population that has been tested in this study will be presented in this chapter.

In general, bilingualism refers to the ability to use more than one language. However, this explanation reflects widely divergent responses to the question of degree (Edwards, 2004). There are many degrees of bilingualism, including being a natural bilingual (i.e., acquiring both languages naturalistically) or an unnatural bilingual (i.e., acquiring one of the languages in a classroom). Therefore, it is essential to define what one means when the term bilingual is used.

Weinrich (1953) defined bilingualism as an alternate usage of two languages. According to Weinrich, bilingualism is related to the high proficiency in which a speaker can switch from one language to another easily.

Baker (1988) questioned the extension of bilingualism. Baker asked whether a student is bilingual if $\mathrm{s} / \mathrm{he}$ is able to understand spoken English and Welsh, and speak English fluently but has problems when s/he speaks Welsh; on the other hand, s/he can read in Welsh and English but to different degrees in both languages, or writes poorly in English and does not have any writing skills in Welsh (Baker, 1988, p.2). With this analogy, Baker extended bilingualism to one's ability to speak, to read, and to write in more than one language.

Recently, more bilingualism studies have put more emphasis on factors such as Age of Acquisition (AoA) and proficiency, and have successfully differentiated the 
differences between bilingual groups (Sabourin, Brien, \& Burkholder, 2014). The separation of bilingual groups will be presented in the following section.

\subsection{Second Language (L2) Acquisition}

\subsubsection{Child L2 Acquisition and Processing}

According to Yip and Matthews (2007), although first language (L1) and second language (L2) sentence processing have been heavily investigated for the last 20 years, it has not been sufficiently shown that L2 sentence processing is similar to L1 sentence processing. Moreover, the nature of L2 knowledge is still unknown; as is the idea that L1 and L2 knowledge have the same epistemology but different processing. Nonetheless, according to Yip, the capacity serving for monolingual acquisition-whether it is innate or otherwise - underlies bilingual acquisition. As a result, studying L2 sentence processing gives insight to L1 sentence processing (Yip \& Clahsen, 1995).

In the late 1970 's, some researchers believed that a child creates a single system for both of his/her languages (Volterra \& Taeschner, 1978). However, more recently, it has been shown that bilingual children can distinguish between typologically related languages such as Spanish and Catalan before age 1 (Bosch \& Sebastian-Galles, 20012003). Another study has demonstrated that the child has separate systems from the outset but these systems develop independently of one another; this is also known as the separate development hypothesis (De Houwer, 1990, 2009). Finally, a child can have separate linguistic systems but these systems influence each other. Child language acquisition for L1 and L2 shows similarities and differences; however, adult L2 acquisition is distinct from child L2 acquisition (Döpke 2000; Yip and Matthews 2007). 


\subsubsection{Adult L2 Acquisition and Processing}

Research on L2 acquisition has thus far shown that Age of Acquisition (AoA) plays a crucial role in adult L2 acquisition and L2 sentence processing. According to Ullman (2001), L1 and L2 sentence processing are distinct because of the differences between the two knowledge systems. L1 speakers have declarative knowledge ${ }^{11}$, knowing what, for the lexicon and they have procedural knowledge ${ }^{12}$, knowing how, of grammar; however, L2 speakers use declarative knowledge for the grammar. This means that L2 speakers who learned their second language in adulthood use rules of grammar as facts. Therefore, if they do not have an advantage of learning their L2 early in their childhood, they have difficulty automatizing it.

\subsection{Typology of Bilingualism}

Two pairs of bilingual groups are most frequently observed in bilingualism studies (Butler, 1996, 2000):

1. Balanced vs. Dominant (Peal \& Lambert, 1962) bilinguals

2. Early vs. Late (Genesee et al., 1978) bilinguals

\subsubsection{Balanced vs. Dominant Bilinguals}

Simultaneous (balanced) and dominant bilinguals are correlated with proficiency level. Balanced bilinguals are those who acquire similar degrees of proficiency in both their native language (L1) and their second language (L2) (Peal and Lambert, 1962).

Dominant bilinguals are those who have higher proficiency in one of their languages. There are many factors that can affect simultaneous and dominant

\footnotetext{
${ }^{11}$ Memories that can be consciously recalled.

12 Unconscious memory of skills and how to do things automatically.
} 
bilingualism, including functional differences related to Age of Acquisition (AoA) and Manner of Acquisition (MoA) (Sabourin, Brien, \& Burkholder, 2014).

Many studies suggest that early AoA enables speakers to keep their L2 abilities, even if the exposure lessens in time. Thus, even if they are not exposed to their L2 for a while later in their life, they are able to preserve their well-established L2 knowledge (Grosjean, 1998).

\subsubsection{Early Bilingualism and Late Bilingualism}

Early and late bilinguals are grouped based on their AoA. Early bilinguals acquire more than one language before the critical / sensitive period (i.e., 0 to 6 ), whereas late bilinguals acquire their L2 after the critical / sensitive period (van Hell \& Dijkstra 2002; Cook, 2003; Meisel 2009). However, it is also possible that late bilinguals can become balanced bilinguals in time, if their exposure is controlled (Lowenthal \& Bull, 1984;

Olson \& Samuels, 1973). And late bilinguals can even have L2 dominance, though this is related to attrition and is beyond the scope of this research.

\subsection{Turkish-English Bilingualism}

Globalisation is one of the most important factors affecting bilingualism (Abutalebi \& Weekes, 2014). English is one of the most widely used languages in popular media and business around the world (Crystal, 1997); speaking English is therefore an asset in European and Middle-Eastern countries. This trend is apparent in Turkey. According to Güneş (2009), during the final years of the Ottoman Empire, the region in which the Republic of Turkey was founded, English was starting to be taught as a secondary foreign language. In 1863, two Americans, C. R. Robert and Cyrus Hamlin, founded Robert College (Istanbul, Turkey), which then separated into Robert College of 
Istanbul (High School) and Bogazici University. These two institutions have been providing education in English since then. In the first years of the Republic of Turkey (1923-1940), while French was the dominant foreign language, after World War II, English as a foreign language was added to formal education in Turkey. Additionally, translations from English to Turkish became more common than translations from French to Turkish. Furthermore, from 1928 to 1935, many internationally-funded institutions were established. In 1938, with the purpose of meeting the high demand for foreign language education in English, Istanbul University opened its first School of Foreign Languages to educate people on foreign language teaching.

Since then, although the amount of English education varied from government to government, English has remained the dominant foreign language of Turkey. Today, English is taught starting from the second year of elementary school in the public system, and kindergarten for private schools. The amount of English teaching still varies across schools and across regions. For example, there are huge differences between public and private schools, such that private schools have the advantage of native English speakers as teachers, while few public schools have this option. Moreover, while coastal and metropolitan cities have higher education quality, many cities in the Anatolian region struggle to find qualified English teachers. From that perspective, although everyone receives the same education, some people have highly proficient English, whereas some do not reach that level due to the different English knowledge levels among English teachers. 
While there are many university programs that provide education in English, there is only one program across universities that can support native-like English: translation and interpretation programs.

\subsection{Simultaneous Interpretation as a Highly Proficient Bilingual Group}

Simultaneous interpreting is a cognitively demanding job because it requires simultaneous comprehension and production. Simultaneous interpreters are known for their eloquent use of more than one language. It is worth noting that many simultaneous interpreters are not early bilinguals. There are mainly late bilinguals of different languages. The task of simultaneous interpreters is to interpret one or more speakers from language $\mathrm{X}$ to language $\mathrm{Y}$. They do not have the time to reformulate their production, as they have to be synchronized with the speaker. They do not have a chance to look up a word in one context while they are interpreting. Moreover, studies show that their working memory is better than any other bilingual group (Christoffels, de Groot, Kroll, 2006).

If we turn back to our previous analysis, we observe that simultaneous interpreters have to be balanced (simultaneous) bilinguals in different languages regardless of their typological differences. Moreover, their comprehension and production periods need to be faster than any other bilinguals because they are performing their job, and the speaker and the audience depend on the simultaneous interpreters' performance. Thus, it is a cognitively demanding and stressful job.

Seleskovitch (1978) claimed that compared to translation, interpreting is approximately 10 times harder. While translating, a translator encounters 2000-3000 
words daily. However, an interpreter has to deal with 20,000 words per day (Seleskovitch 1978:22).

Paradis (1994) claims that simultaneous interpreters are required to perform tasks that bilinguals avoid doing, such as activating both languages. When becoming bilingual, an individual does not only master two languages — s/he also masters the relationship between the two languages. Recently, bilingual cognitive control has been investigated; the findings have suggested that bilinguals, depending on their L2 acquisition, show differences for cognitive control (Green, 2011).

The challenging part of being bilingual is controlling the languages. Bilinguals are often required to switch between languages depending on the environment. As they are doing so, they have to control activation from the non-selected language in order to speak the other language accurately.

Paradis (1984) created two hypotheses to explain this activation: (i) Subset Hypothesis and (ii) Activation Threshold Hypothesis. The subset hypothesis suggests that bilinguals' two languages are subserved by two subsytems of another larger cognitive system known as implicit language competence. According to this model, each language's subsystem has a similar nature to the other language's subsystem. However, these subsystems are epistemologically and naturally different from other cognitive systems. Paradis suggests that all these small subsytems form a connection network between each other, and may be independently activated or inhibited.

On the other hand, the activation threshold hypothesis suggests that comprehension and production are similar processes. Thus, the more frequently a token is 
used, the lower the activation threshold, or the longer it has been since a token was last activated, the more difficult it is to activate.

When it comes to simultaneous interpreters, who are at an advanced level of being a bilingual, controlling which language they are using becomes more challenging because the interpreter has to keep both languages active in order to comprehend a sentence in the source language and translate it into the target language.

In this case, if the subsystem hypothesis holds, simultaneous interpreters' subsystems should be connected with strong networks. On the other hand, if the activation threshold hypothesis holds, simultaneous interpreters have to keep both languages activated to prevent the activation costs.

Since these issues are still being explored, this study specifically aims at testing simultaneous interpretation students, who are required to be high proficient in English and in Turkish. 


\section{Chapter: Methodology}

In the previous chapters, the issues regarding shared syntax account were discussed both theoretically, as in the case of generative grammar, and empirically, as in the case of syntactic priming studies. It has been made clear that a central problem with the shared syntax account is limitations in research with typologically different languages.

Yet we know that there is a specific bilingual population, simultaneous interpreters, who have to work with at least two languages regardless of their typological similarities. If one were to apply the shared syntax account to a bilingual group such as simultaneous interpreters, an extended version of the shared syntax account that can successfully account for typologically dissimilar languages is required.

The typologically different language pair being examined in this study is Turkish and English. While Turkish and English differ in many linguistic areas (e.g., phonology, morphology and syntax), these languages also have different word orders that can complicate the acquisition of English for Turkish speakers. The word order differences are broad between the two languages; English has strict Subject-Verb-Object word order, whereas Turkish has Subject-Object-Verb word order but also it allows for word scrambling (i.e., free word order).

Ditransitive verbs were given as an example of the word order variation between the two languages. If the shared syntax account is accurate, a Turkish-English bilingual can use his/her knowledge of word order to create two structures in English. Although PO and DO structures have unique syntactic structures, their semantics are identical for some ditransitive verbs (e.g., send) in English. Therefore, using PO and DO structures 
focuses the experiment on syntactic knowledge if Turkish-English bilinguals distinguish the syntactic variances between two structures.

The design of this study included two judgment tasks: (i) within language sentence sameness, and (ii) cross-language correct translation. Comprehension-based tasks were chosen over production-based tasks to eliminate the use of translation strategies, since simultaneous interpreters have more linguistic awareness about languages compared to other bilingual populations. Likewise, they are well known for their quick and precise linguistic analyses. Thus, in a picture-naming task ${ }^{13}$, simultaneous interpreting students could over-interpret the pictures, and that could result in different interpretations of the data. Additionally, language processing in simultaneous interpreters has not been analyzed in detail, because production data without any comprehension data would be difficult to interpret. To prevent these problems, a sentence sameness judgment task (syntactic and semantic) and a correct translation judgment task were designed to test whether this specific bilingual population shares prepositional object (PO) and double object (DO) sentences within and across languages.

To investigate whether Turkish-English simultaneous interpretation students have a shared syntax for PO and DO sentences, sameness (Experiment 1 and 2), and correctness (Experiment 3 and 4) judgments were collected, as well as Reaction Times (RTs) in giving their responses. In Experiments 1 and 2, participants heard two sentences consecutively and had to judge whether they were the same or not. When they made a decision, their RTs were collected. There were two conditions: (i) a match where the two sentences were identical (PO-PO and DO-DO), and (ii) a mismatch where one was a PO

\footnotetext{
${ }^{13}$ Recall that the picture-naming task is generally used in the investigation of shared syntax account.
} 
sentence and the other was a DO sentence or vice versa (PO-DO and DO-PO). This was done in English (Experiment 1) and in Turkish (Experiment 2). There were two ways to judge a sentence pair in terms of sameness. Participants either picked semantic sameness, in which they picked the global meaning of the two sentences, or they picked syntactic sameness, which would mean that they were able to recognize the syntactic differences between PO and DO sentences, even though they were semantically the same.

Table 1. The Design of the Experiment

Conditions Design

\begin{tabular}{lc}
\hline PO-PO (match) & $\begin{array}{c}\text { Semantically \& } \\
\text { syntactically the sam }\end{array}$ \\
DO-DO (match) &
\end{tabular}

PO-DO (mismatch) Semantically the same,

DO-PO (mismatch) syntactically different

For Experiment 3 and Experiment 4, participants again heard two sentences consecutively but in different languages, and had to judge whether the second sentence was the correct translation of the previous sentence. In Experiment 3, an English sentence was followed by a Turkish translation. In experiment 4, a Turkish sentence was followed by an English translation. When the participants made a decision, their RTs were collected. In these experiments, there were again match and mismatch conditions. There were two ways to judge a sentence pair in terms of correct translation. If, in this crosslinguistic version, participants had judged PO-PO and DO-DO pairs to involve incorrect translations, it showed that they could not understand the sentences in either the target language or in the source language. Moreover, these participants might have gone beyond 
the experiment, and found unrelated reasons for the mismatch ${ }^{14}$. Participants either picked a semantic translation, in which they picked the global meaning of the two sentences and pressed "correct translation", or they picked the syntactic translation, which means that they could recognize the syntactic differences between PO and DO sentences cross-linguistically. Experiment 3 and Experiment 4 use a similar design to Experiment 1 and 2, hence it is testing syntactic and semantic similarities but this time cross-linguistically.

\subsection{Hypotheses and Predictions}

Four different tests were created for this study: sameness judgments within English, sameness judgments within Turkish, correct translation from English to Turkish, and correct translation from Turkish to English. The aim of the sameness judgments tasks was to see whether Turkish-English bilinguals' Turkish judgments or English judgments are affected by each other. If there is a syntactic interaction between two languages, it will show a shared syntax for Turkish-English bilinguals.

The aim of the correct translation tasks was to see whether Turkish-English bilinguals can show the same interaction when two languages are both active. If their Turkish and English interact, their correct translation judgments can be mixed for PO and DO sentences cross-linguistically, because in English, PO and DO sentences are easy to be differentiated, but in Turkish, their difference is hard to recognize.

\footnotetext{
${ }^{14}$ All sentences in English had a definite or indefinite determiner. Turkish does not separate definite and indefinite determiners; however, participants who had found PO-PO and DO-DO pairs as incorrect might have thought about the determiner selection for a more accurate translation.
} 


\subsubsection{Experiment 1 (English-English)}

In Turkish, PO and DO sentences are syntactically the same (i.e., same word order), whereas in English, they are syntactically different. So for mismatch conditions (EPO-EDO or EDO-EPO), if participants judge the mismatched pairs to be as similar as the matched pairs, this shows that they disregard syntactic differences and use the global meaning of the PO and DO sentences in English because they only have Turkish PO and DO structures. This does not however entail a shared syntax, because in this case, they are using their Turkish knowledge to process PO and DO sentences semantically in English. Therefore, they fail to show a shared syntax but show a shared semantics.

I anticipate that mid and low proficiency bilinguals will judge mismatch conditions to be as similar as match conditions, because it has been previously shown that low proficiency L2 speakers prefer semantic information over syntactic information (Lim \& Christiansen, 2012). On the other hand, I anticipate that high proficiency bilinguals will judge the mismatched pairs to be less similar because of the overtly marked syntactic differences between PO and DO sentences in English (i.e., PO sentences have an extra preposition). If participants judge mismatched pairs (EPO-EDO or EDO-EPO) to be less similar than matched pairs (EPO-EPO or EDO-EDO), it will show that they are accounting for the syntactic dissimilarities between PO and DO sentences in English, even if they have a default knowledge of PO and DO sentences to be syntactically similar in Turkish. This suggests a shared syntax because they have the default knowledge of Turkish PO and DO sentences, and they have a new knowledge of English PO and DO sentences. This may look like a separate syntax, however, they can separate them from Turkish PO and DO structures. 
If Turkish-English bilinguals judge mismatched pairs slower than matched pairs, it will show that participants realize the syntactic differences between PO and DO sentences. Therefore, it is expected that mismatch conditions take more time to be judged compared to match conditions.

For match and mismatch conditions, the frequency of structures may affect the sameness judgments or reaction times. It is expected that low proficiency TurkishEnglish bilinguals will judge DO-DO pairs to be less similar than PO-PO pairs due to the low frequency of DO sentences. I expect to see that PO final mismatch pairs (i.e., EDOEPO) are processed faster than DO final mismatch pairs (i.e., EPO-EDO) by all participants, because PO sentences are used more frequently, therefore, they can be processed faster when compared to DO sentences.

Overall, if high proficiency bilinguals judge the mismatch conditions to be less similar, and mid and low proficiency bilinguals judge them to be more similar or as similar as match conditions, it will show that proficiency plays a role in L2 processing cross-linguistically.

\subsubsection{Experiment 2 (Within Turkish)}

If participants judge the mismatch conditions (TPO-TDO or TDO-TPO) to be as similar as match conditions, then it will show that they do not have a word order preference for Turkish ditransitive verbs, and they accept both PO and DO word orders without differentiating the focus position. This suggests that these participants do not have a shared syntax; if they had a shared syntax, their Turkish judgments would show some interaction with their English syntax, and they would become more aware of the 
focus position. Thus, if they judge the mismatch conditions to be as similar as match conditions, then they have a separate syntax for Turkish and for English. Mid and low proficiency participants are expected to judge mismatch conditions to be as similar as match conditions due to a low interaction between their L1 and L2 grammar.

On the other hand, as a result of their L2 proficiency, high proficiency bilinguals are expected to judge mismatch conditions to be less similar than match conditions due to a possible interaction between their L1 and L2, and their proficiency both in English and in Turkish (i.e., realizing focus differences). If these participants judge the mismatch conditions to be less similar than match conditions, then it will show that they have a shared syntax for PO and DO sentences. This means that their L2 and L1 interact at some point, and with this interaction they can become more sensitive to their first language because, although Turkish does not have overt syntactic differences (i.e., same word order and case marking) for PO and DO sentences, at the underlying level, PO and DO sentences are syntactically different because the focus changes based on the object position.

If participants react faster to either PO or DO sentences in Turkish, it will show that the faster-reacted word order in Turkish may be the preferred word order for Turkish ditransitive verbs. Since PO and DO structures are marked similarly in Turkish, I do not anticipate seeing RT differences.

Overall, if high proficiency Turkish-English bilinguals find mismatch pairs to be less similar, and mid proficiency and low proficiency Turkish-English bilinguals find mismatch pairs to be equally or more similar within English and within Turkish, it will show that proficiency plays a key role in shared syntax. 


\subsubsection{Experiment 3 (English-Turkish) and Experiment 4 (Turkish-English)}

If participants judge the mismatch conditions to be as correct translation as the match conditions, then it will show that they cannot follow the differences between PO and DO sentences cross-linguistically. Since both English and Turkish stay active during the translation task, this task is more difficult than the previous sameness judgment task; that is why it may be hard for participants to keep track of the structural nuances, and since it is a translation task, they may be purposefully focusing on the meaning. Especially, it will be hard for participants to judge mismatch pairs because Turkish does not mark PO and DO sentences as English does. At this point, participants may have other cognitive difficulties in interpreting the two sentences, such as working memory, word choice, and prepositions.

If participants judge the mismatch conditions to be the less correct translation than the match conditions, then it will show that Turkish-English bilinguals can process PO and DO sentences cross-linguistically. This suggests that they can follow the structural changes in English through word order variations in Turkish ${ }^{15}$.

I expect seeing slight differences across the three different proficiency groups. I anticipate that high proficiency bilinguals will find the mismatch conditions as the "incorrect translation", whereas I do not expect it from mid proficiency and low proficiency participants. In terms of RTs, since the translation task is difficult, it is expected that Turkish-English bilinguals' reactions to match and mismatch conditions will be similar. I anticipate seeing longer RTs in the translation tasks compared to the

\footnotetext{
15 Please note that a male voice was used for English sentences, and a female voice was used for Turkish sentences. This might also affect participants' judgments. A male voice and a female voice was purposefully used to make the translation task more natural, as during a translation task, students may translate from a male or a female voice, and they have to process them simultaneously.
} 
first two experiments, since translation is more cognitively demanding (this applies to Experiment 3 and Experiment 4).

\subsection{Overall Experimental Design and Procedure}

\subsubsection{Recruiting and Participant Selection}

The target population for both experiments was comprised of Turkish speakers between the ages of 18 and 35, whose second language is English, and native speakers of English as a control group. A total of 53 participants were tested in Turkey as the experimental group, and 15 native speakers of English were tested as the control group in Ottawa (Canada). All participants were required to have normal or corrected-to-normal vision. This was required because participants pressed a button right after they saw a fixation cross on the screen. Participants' data were excluded from analyses if exposure to other languages was significant or occurred during infancy. This resulted in $9.4 \%$ of data loss. For Experiments 1 and 2, if participants judged half of the items to be the same and half of the items to be different overall, they were excluded from the analysis. This resulted in $18.7 \%$ of data loss. No such exclusion was applied to Experiments 3 and 4 due to the effect of translation. In terms of RTs, for Experiments 1 and 2, any trial that took longer than $1500 \mathrm{~ms}$ was excluded. This resulted in $0.53 \%$ of data loss. For Experiments 3 and 4 , any trial that took longer than $3000 \mathrm{~ms}$ was excluded. This resulted in $0.99 \%$ of data loss. ${ }^{16}$

Turkish-English bilinguals were recruited from Turkey via the Turkish Translation Studies Student Association. An invitation was sent through the association.

\footnotetext{
16 The scale for RTs was between 1500ms (for Experiment 1 and 2) and 3000ms (for Experiment 3 and 4 ). Since this group of participants was tested for the first time, RTs faster than $1500 \mathrm{~ms}$ were not used as the limit for this study. The main purpose of this study was to provide baseline information for future studies.
} 
Students from Ege University English Translation Studies Department (Izmir, Turkey), Trakya University English Translation Studies Department (Edirne, Turkey) and Istanbul University English Translation Studies Department (Istanbul, Turkey) volunteered to participate in this study. Participants were thanked for their participation. All participants had completed at least 3 semesters in their programs. No senior year participants were tested because they were attending exchange programs or enhanced translation training. The following table shows the participants' mean ages across three different cities.

Table 2 The Distribution of Participants and Mean Age

City of Participation

Edirne, Turkey

Istanbul, Turkey

Izmir, Turkey
Mean Age 21

19

20

\section{Total $n$}

16

6

17

English native speakers were recruited via the University of Ottawa ISPR (University of Ottawa subject pool) system. Participants received one course credit for their participation (see Appendix A for ISPR recruitment). Participants significantly exposed to any languages other than English from birth were excluded from the study. As Ottawa is an English-French bilingual city, all participants who grew up in Ottawa were exposed to French after the age of 4, as the education system requires having French as a second language. Those participants were not excluded. However, participants who were exposed to French from birth or who had been in a French immersion program, where French exposure is greater than or equal to English, were excluded from the study. 


\subsubsection{Groups}

Before starting the experiment, participants read and, if they accepted, signed the consent form (see Appendix B). After signing the required consent form, every participant filled out a language background questionnaire. This questionnaire required participants to indicate any and all language(s) learned, their AoA (Age of Acquisition), their proficiency, the proportion of languages they use in different contexts, the language(s) that their parents used to interact with them since birth, when they felt that they had become bilingual, if their language had changed over time, percentage(s) of language(s) used by influential members of their family and how often they interacted with these family members in their childhood, the main language of instruction for various levels of education versus the language of classes taken. If there was unclear information, a short interview was conducted by the experimenter before the experiment began. After the language background questionnaire and attending the experiments, participants were given Brown's (1980) English cloze test testing general language proficiency. This cloze test was used to assign appropriate proficiency levels to the participants. The same proficiency groups were used in all experiments.

Based on the cloze test results and language background questionnaire, participants were allocated to one of three groups for inclusion in the analysis (high: missing one or two determiners or prepositions; mid: missing determiners, prepositions and tense; low: missing many determiners, prepositions, tense and choosing a wrong syntactic category) or they were excluded from the analysis due to ineligibility. As this study is being treated as a pilot study, and its aim is to look for preliminary effects, the 
numbers are low. The following table shows the distribution of the proficiency groups by cloze test results:

Table 3 The Distribution of the Participants by Proficiency

Proficiency Cloze Test Score n (out of 50)

\begin{tabular}{lcc}
\hline High Proficiency & $\geq 35$ & 13 \\
Mid Proficiency & $20-34$ & 21 \\
Low Proficiency & $\leq 19$ & 11 \\
\hline
\end{tabular}

\subsection{Stimuli}

All sentences in Turkish were pre-recorded by a female native speaker of Turkish and all sentences in English were pre-recorded by a male native speaker of Canadian English. Audacity, an audio program, was used to record the sentences, which were then split into sound files by using Praat, another audio program.

All of the sentences used in the four experiments in the study are represented separately in Tables 5- 8. Filler sentences were composed of passive and active sentences with prepositional or double object sentences. The filler constructions also had two conditions (same and different) and 4 sub-conditions (PassivePO-PassivePO, PassiveDOPassiveDO, PassivePO-PassiveDO, PassiveDO-PassivePO). Excel randomization was used to randomize the stimuli and filler sentences. 
Table 4 Examples of Experiment 1

\begin{tabular}{|c|c|c|}
\hline Language & Conditions & Example \\
\hline English-English & PO-PO & $\begin{array}{l}\text { John gave the book to Mary. } \\
\text { John gave the book to Mary. }\end{array}$ \\
\hline English-English & DO-DO & $\begin{array}{l}\text { John gave Mary the book. } \\
\text { John gave Mary the book. }\end{array}$ \\
\hline English-English & PO-DO & $\begin{array}{l}\text { John gave the book to Mary. } \\
\text { John gave Mary the book. }\end{array}$ \\
\hline English-English & DO-PO & $\begin{array}{l}\text { John gave Mary the book. } \\
\text { John gave the book to Mary. }\end{array}$ \\
\hline
\end{tabular}

Table 5 Examples of Experiment 2

\begin{tabular}{|c|c|c|}
\hline Language & Conditions & Example \\
\hline Turkish-Turkish & PO-PO & $\begin{array}{l}\text { Ali kitab-ı Ayșe-ye verdi. } \\
\text { Ali book } \\
\text { 'Ali gave the book to Ayse.' } \\
\text { Ali kitab-1 Ayșe-ye verdi. }\end{array}$ \\
\hline Turkish-Turkish & DO-DO & $\begin{array}{l}\text { Ali Ayşe-ye kitab-ı verdi. } \\
\text { Ali Ayse }{ }_{D A T} \text { book } \\
\text { 'Ali gave the book to Ayse.' } \\
\text { Ali Ayşe'ye kitabı verdi. }\end{array}$ \\
\hline Turkish-Turkish & PO-DO & $\begin{array}{l}\text { Ali kitab-1 Ayşe-ye verdi. } \\
\text { Ali book }{ }_{A C C} \text { Ayse }{ }_{D A T} \text { gave } \\
\text { 'Ali gave the book to Ayse.' } \\
\text { Ali Ayşe-ye kitab-ı verdi. } \\
\text { Ali Ayse } \\
\text { 'Ali gave book the book to Ayse.' }\end{array}$ \\
\hline Turkish-Turkish & DO-PO & $\begin{array}{l}\text { Ali Ayşe-ye kitab-ı verdi. } \\
\text { Ali Ayse } \text { DAT book }_{\text {ACC }} \text { gave } \\
\text { 'Ali gave the book to Ayse.' } \\
\text { Ali kitab-1 Ayşe-ye verdi. } \\
\text { Ali book } \\
\text { 'Ali gyse } \text { Ayse the book to Ayse.' }\end{array}$ \\
\hline
\end{tabular}


Table 6 Examples of Experiment 3

\begin{tabular}{|c|c|c|}
\hline Language & Conditions & Example \\
\hline English-Turkish & PO-PO & $\begin{array}{l}\text { Ali gave the book to Ayse. } \\
\text { Ali kitab-ı Ayşe-ye verdi. } \\
\text { Ali book }{ }_{\text {ACC }} \text { Ayse } \text { DAT }_{\text {gave }} \\
\text { 'Ali gave the book to Ayse.' }\end{array}$ \\
\hline English-Turkish & DO-DO & $\begin{array}{l}\text { Ali gave Ayse the book. } \\
\text { Ali Ayşe-ye kitab-ı verdi. } \\
\text { Ali Ayse }{ }_{\mathrm{DAT}} \text { book } \mathrm{ACC} \text { gave } \\
\text { 'Ali gave the book to Ayse.' }\end{array}$ \\
\hline English-Turkish & PO-DO & $\begin{array}{l}\text { Ali gave the book to Ayse } \\
\text { Ali Ayşe-ye kitab-ı verdi. } \\
\text { Ali Ayse }{ }_{D A T} b_{\text {book }} \text { gave } \\
\text { 'Ali gave the book to Ayse.' }\end{array}$ \\
\hline English-Turkish & DO-PO & $\begin{array}{l}\text { Ali gave Ayse the book. } \\
\text { Ali kitab-ı Ayşe-ye verdi. } \\
\text { Ali book }{ }_{A C C} \text { Ayse } e_{D A T} \text { gave } \\
\text { 'Ali gave the book to Ayse.' }\end{array}$ \\
\hline
\end{tabular}

Table 7 Examples of Experiment 4

\begin{tabular}{|c|c|c|}
\hline Language & Conditions & Example \\
\hline Turkish-English & PO-PO & $\begin{array}{l}\text { Ali kitab-ı Ayşe-ye verdi. } \\
\text { Ali book } \text { ACC }_{\text {Ayse }} \text { DAT gave } \\
\text { 'Ali gave the book to Ayse.' } \\
\text { Ali gave the book to Ayse. }\end{array}$ \\
\hline Turkish-English & DO-DO & $\begin{array}{l}\text { Ali Ayşe-ye kitab-ı verdi. } \\
\text { Ali Ayse }{ }_{D A T} \text { book }_{A C C} \text { gave } \\
\text { 'Ali gave the book to Ayse.' } \\
\text { Ali gave Ayse the book. }\end{array}$ \\
\hline Turkish-English & PO-DO & $\begin{array}{l}\text { Ali Ayşe-ye kitab-ı verdi. } \\
\text { Ali Ayse } \text { book }_{\text {ACC }} \text { gave } \\
\text { 'Ali gave the book to Ayse.' } \\
\text { Ali gave the book to Ayse. }\end{array}$ \\
\hline Turkish-English & DO-PO & $\begin{array}{l}\text { Ali kitab-ı Ayşe-ye verdi. } \\
\text { Ali book }{ }_{\text {ACC }} \text { Ayse }{ }_{D A T} \text { gave } \\
\text { 'Ali gave the book to Ayse.' } \\
\text { Ali gave Ayse the book. }\end{array}$ \\
\hline
\end{tabular}

There were 576 sentences in total, half of which were experimental and half of which were filler items. The stimuli sentences consisted of $72 \mathrm{PO}$ and $72 \mathrm{DO}$ sentences in English, and the same number of sentences in Turkish. Each experiment had 36 trials.

Each experiment had 2 conditions (match-mismatch) separated into four sub-conditions 
(i.e. PO-PO, DO-DO, PO-DO, DO-PO). Initially, each condition had 9 experimental trials within an experiment. However, due to a technical problem in the audio file some conditions got 10 items, some had 8 items. The percentage proportion was used to balance items $(\mathrm{PO}-\mathrm{PO}=10, \mathrm{PO}-\mathrm{DO}=8, \mathrm{DO}-\mathrm{PO}=10, \mathrm{DO}-\mathrm{DO}=8)$. All sentences were also balanced in length and complexity within and across languages. Only simple declarative sentences were used. The frequency of the words was also controlled both in English and in Turkish. As discussed in the Chapter 3, sentences were controlled for causativity and animacy to prevent other interpretations of $\mathrm{PO}$ and $\mathrm{DO}$ sentences. Two tenses were used to lessen the effect of tense repetition. 144 sentences were produced with future tense in English and in Turkish; 144 sentences were produced with past tense in English and in Turkish.

The following sentences are examples of each filler condition.

a) $\mathrm{EPO}_{\text {passive: }} \quad$ The cookie was given to the twins.

b) $\mathrm{EDO}_{\text {passive: }}$ The twins were given the cookie.

c) $\mathrm{TPO}_{\text {passive: }} \quad$ Kurabiye ikiz-ler-e ver-il-di. cookie twin-PL-DAT give-PASS-PAST 'The cookie was given to the twins.'

d) TDO passive: Ikiz-ler-e kurabiye ver-il-di. twin-PL-Dat cookie give-PASS-PAST 'The twins were given the cookie.'

\subsection{Procedure}

Participants heard two sentences consecutively, which included either PO and DO sentences or control sentences (i.e. active/passive prepositional or double object sentences). When the second sentence concluded, a fixation cross appeared on the screen 
for $500 \mathrm{~ms}^{17}$, and then participants pressed a button to decide whether the two sentences were the same or not.

The method for all four experiments was the same, except that Experiment 1 also included testing native speakers as the control group. Participants sat down in front of a laptop (Dell Inspiron). They were instructed to listen to two sentences consecutively. After the second sentence, they were asked to make a judgment and press a button. For Experiment 1 (English-English) and Experiment 2 (Turkish-Turkish) participants were asked whether the two sentences were the same or not. If the second sentence was the same as the first one, they were instructed to press 2 , and if the second sentence was not the same as the first one, they were instructed to press 1. For Experiment 1, half of the control group was also asked whether the two sentences had the same meaning. For Experiment 3 (English-Turkish) and Experiment 4 (Turkish-English), participants were asked whether the second sentence was the correct translation of the first one. If it was the correct translation they were instructed to press 2 ; if it was not the correct translation they were instructed to press 1 . The RTs and sentence sameness (Experiment 1 and 2) or correct translation (Experiment 3 and 4) judgments were collected. The order of the test was counter balanced between participants (i.e., participant 1 started from the Experiment and continued Experiment 2, Experiment 3, and Experiment 4), and participant 2 started from the Experiment 2, and continued Experiment 3, Experiment 4, Experiment 1). Some participants could not attend all four experiments. Each experiment lasted approximately 10 minutes. The data from all the experiments were analyzed using IBM's SPSS program.

\footnotetext{
17 The aim of the fixation cross was to prevent pressing a button before the second sentence was completed.
} 


\section{Chapter: Results}

\subsection{Results for Experiment 1 (English-English)}

\subsubsection{Sameness Judgment}

A total of 21 bilingual participants and 15 native English speakers completed this experiment. The bilingual participants were grouped in terms of their proficiency; there were $N=4$ high proficiency bilinguals, $N=10$ mid proficiency, and $N=7$ low proficiency bilinguals. Participants' sameness judgments and RTs were collected. The control group $(N=15)$ was separated into two groups. One group $(N=8)$ was asked whether the two sentences have the same meaning (in English), the other group $(N=7)$ was asked whether the two sentences are the same or not. The reason for this separation was to control whether the native speakers of English would find PO and DO sentences structurally different, when asked about the sameness, and semantically identical when asked about the meaning.

Results for Native English Control Group

The 15 participants were all native speakers of English, grouped in terms of the question that they got. Mixed ANOVAs were conducted to compare the effect of condition (match and mismatch) on the sameness judgments within English. The question type (i.e., are they the same, do they mean the same) was used as a between subject factor. There was a significant effect of condition type on sameness judgments, $F(3,11)=$ $97.3, \mathrm{p}<.001$. The interaction between the conditions and the question type was also significant, $F(3,11)=44.1, \mathrm{p}<.001$. This shows that native speakers of English judged mismatch conditions to be different, when they were asked about the sameness. On the 
other hand, native speakers of English judged mismatch conditions to be as similar as match conditions, when they were asked about the sameness of the meaning. This separation also shows that when asked about the sameness, Turkish-English bilinguals (mainly high proficiency ones) are expected to judge the mismatch conditions to be different, if they have a shared syntax.

The data from the control group showed that when native speakers of English were asked whether the two sentences were the same, they found EDO-EDO significantly less similar than EPO-EPO (see Figure 3). The pairwise comparisons showed that EPOEPO sentences were found more similar than EDO-EDO ones $(M D=9.7, S E=1.4, p<$ $.001)$. No such difference happened when they were asked about the meaning $(M D=$ $.781, S E=3.4, p=.826)$. These results suggest that native speakers of English found some EDO sentences less correct because this only happened in the match conditions (EDO-EDO). It can be related to the nature of the DO sentences. As I discussed earlier, DO sentences are more sensitive to definiteness and to animacy. Although all sentences were created with an animate goal phrase (e.g., to Mary, to him, to John), English native speakers may have found some EDO sentences difficult to understand due to the low frequency of their usage.

Results for Turkish-English Bilingual Participants

Mixed ANOVAs were conducted to compare the effect of condition (match and mismatch) on the sameness judgments within English for Turkish-English bilinguals. Proficiency level was used as a between subject factor. There was a significant effect of 
condition type on the sameness judgments, $F(1.3,23)=24.1 p<.001$, showing that mismatch conditions were found less similar than match conditions.

There was no significant effect of Proficiency on conditions $F(2,18)=3.1 p=$ 0.67. However, this can be related to the sample size of high proficiency bilinguals or the unevenness of the sample size. Due to the low number of high proficiency bilinguals, proficiency may not be significant. However, Figure 3 below shows that participants from different proficiency levels behaved slightly differently. Moreover, multiple comparisons of proficiency shows that overall low proficiency bilinguals' means for all conditions is higher than high proficiency bilinguals' mean average ( $M D=-24.5, S E=$ $9.3, p=.057$ ), and mid proficiency bilinguals' means for all condition is higher than high proficiency bilinguals $(M D=18.1, S E=9.3, p=.207)$ but lower than low proficiency bilinguals $(M D=-6.5, S E=7.7, p=1.000)$. Thus, while it was predicted that only high proficient bilinguals would judge the mismatch sentences to be less similar than the match sentences, this was found to be true for all three proficiency levels. However, there is a trend in the predicted direction, with the mid and low proficiency bilinguals showing less of a difference between the match and mismatch conditions compared to the high proficiency bilinguals (see Figure 3).

Pairwise comparisons between conditions showed that there was a significant difference in the sameness judgment for PO and DO sentences. Participants found EPOEPO pairs more similar than EDO-EDO pairs $(M D=2.2, S E=.288, p<.001)$. This was true for all three proficiency levels, although it was predicted only for the low proficiency bilinguals. This shows that Turkish-English bilinguals had difficulties processing DO 
sentences. Moreover, participants judged EPO-EDO pairs $(M=54.9, S E=4.1)$ less similar than EDO-EPO pairs $(M D=-1.8, S E=.416, p=.002)$. This shows that participants judged the mismatch conditions (EPO-EDO, EDO-EPO) differently, and this difference can be related to the final sentence; since it would be harder for them to remember the previous sentence in a mismatch condition, when participants heard EDO sentences, their sameness judgment decreased. Also the control data showed that EDO sentences might be different from EPO sentences (i.e., in terms of frequency and definiteness).

\section{Comparison of Bilingual and Control Groups}

These results suggest that there is a trend showing a difference between the high and low proficiency bilinguals' judgments. While high proficiency bilinguals found mismatch conditions (EPO-EDO, EDO-EPO) less similar, low proficiency bilinguals did not distinguish match and mismatch conditions. They found all conditions the same. This shows that while high proficiency bilinguals have started to distinguish the syntactic differences, low proficiency bilinguals have not yet achieved this. Or alternatively, the three groups might have interpreted the task differently, with the mid and low proficiency bilinguals looking at the meaning, and high proficiency bilinguals looking at the structure.

Figure 3 shows the comparisons of the two groups of native speakers (are they the same, do they mean the same) for high, mid and low proficiency participants. The results show that high proficiency bilinguals and native speakers (asked about 'the sameness') judged the mismatch conditions (i.e., EPO-EDO, EDO-EPO) to be different. Note that 
the native speakers group did not judge any mismatch pairs to be the same, which is why there are no bars on the chart for EPO-EDO and EDO-EPO conditions. However, the mid and low proficiency speakers and the other half of the native speakers (asked about the 'sameness of the meaning') judged mismatch conditions to be the same. All error bars (from Figure 3-9) show the standard error.

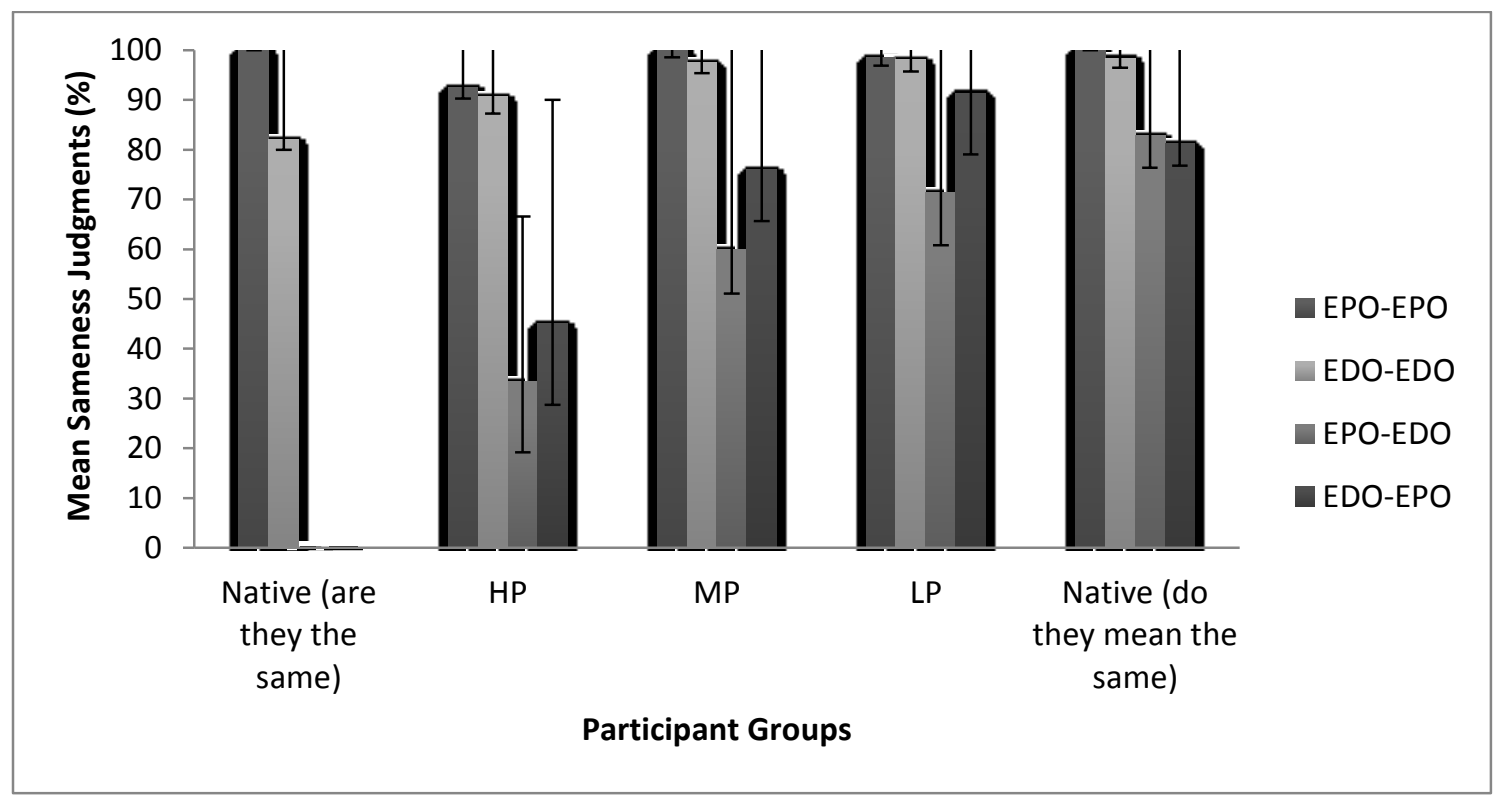

Figure 3 Sameness Judgments (\%) of all Participants in Experiment (within English)

\subsubsection{Reaction Times}

\section{RTs for Native English Control Group}

Mixed ANOVAs were conducted to compare the effect of condition (match and mismatch) on the sameness judgments within English. Question type was used as a between subject factor. There was a significant effect of condition on the question type, $F(3,11)=3.8, p=.043$. This shows that when asked about sameness or sameness in meaning, participants' RTs showed differences. Participants’ RTs were slightly slower when asked about the sameness $(M=461.4 \mathrm{~ms}, S E=61.5 \mathrm{~ms})$ compared to when they 
were asked whether two sentences had the same meaning $(M=412.3 \mathrm{~ms}, S E=57.5 \mathrm{~ms})$. This may support the idea that PO and DO sentences have the same meaning in English, but they have different syntactic representations.

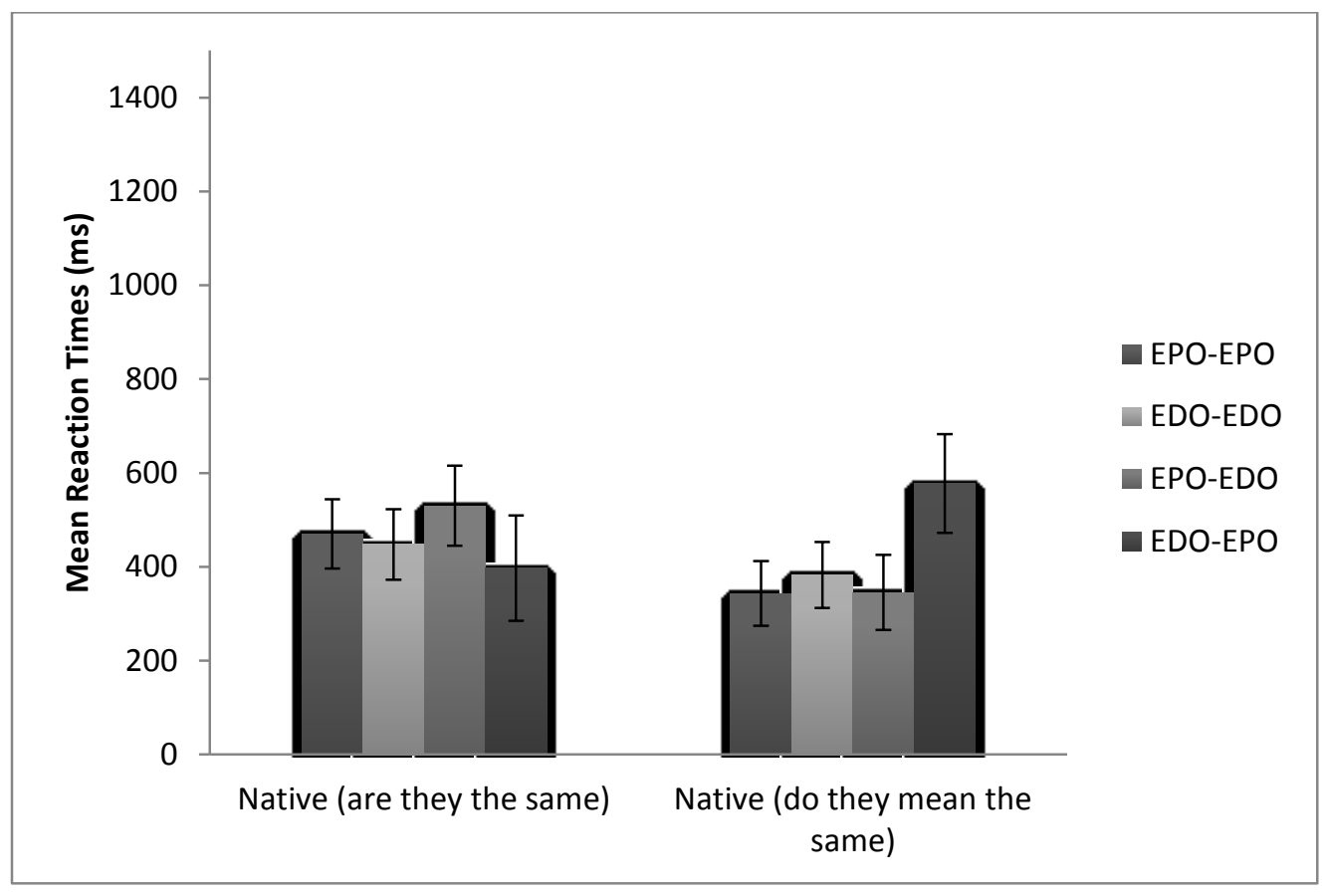

Figure 4 Reaction Times (ms) of the Control Group

RTs for Turkish-English Bilingual Participants

Mixed ANOVAs were conducted to compare the effect of condition (match and mismatch) on the reaction times (RTs) of the bilingual participants within English. Proficiency level was used as a between subject factor. A significant effect was found based on condition type, $F(1.3,23)=7.9, p<.001$. Pairwise comparisons between conditions showed that there was a significant difference between match and mismatch conditions. As expected, participants judged EPO-EPO and EDO-EDO pairs more quickly than EPO-EDO and EDO-EPO pairs $(M D=385.9, S E=94.2, p=.003)$. 
While it was predicted that EDO-EPO sentences would be judged faster than EPO-EDO sentences, the results show that the differences were not significant.

Furthermore, no significant result was observed in terms of proficiency $(F(2,18)=.203$, $p=.818)$. This could be the result of the low number of high proficiency bilinguals ( $N=$ 4). As shown in Figure 5, in the mismatch conditions low proficiency bilinguals reacted slightly slower to the DO final sentences compared to mid proficiency bilinguals, and high proficiency bilinguals were the fastest for DO final sentences. This can be an indicator of the change in language acquisition. Recall that participants started their university education by having English as a foreign language. Thus, they learned PO sentences but not DO sentences, and that is the reason why PO sentences are more frequently used. Moreover, PO is marked with a preposition in English but DO is not marked. Therefore, there is a link between proficiency and how well they have learned what they are taught in school, such as DO sentences.

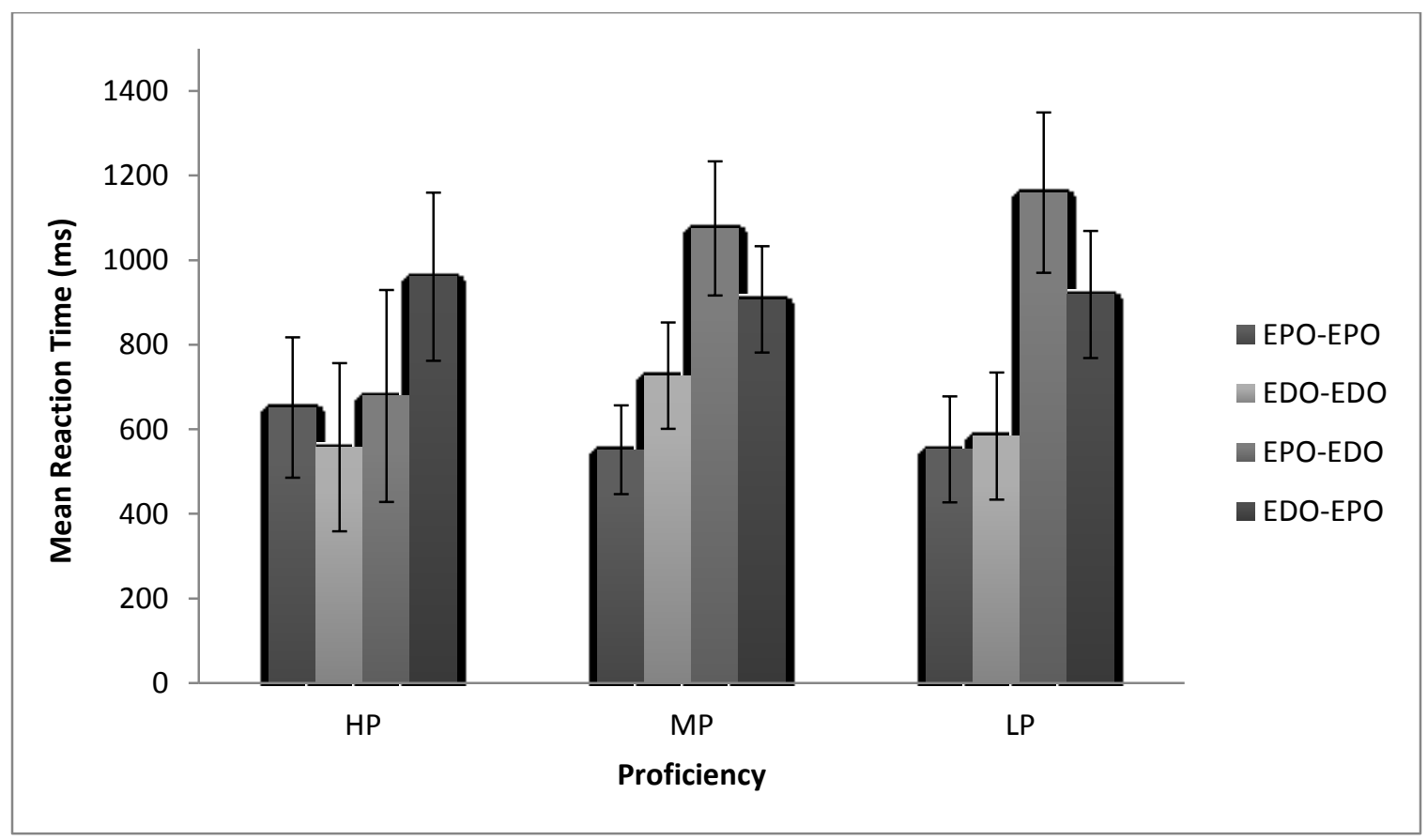

Figure 5 Reaction Times (ms) for Each Condition by Proficiency in Experiment 1 (within English) 


\subsection{Results for Experiment 2 (Turkish-Turkish)}

The same bilingual participants as in Experiment 1 participated in this experiment ( $N=4$ high proficiency bilinguals, $N=10$ mid proficiency, and $N=7$ low proficiency bilinguals). Participants' sameness judgments and RTs were collected.

\subsubsection{Sameness Judgment}

Mixed ANOVAs were conducted to compare the effect of conditions (match and mismatch) on sameness judgments within Turkish. Proficiency level was used as a between subject factor. There was a significant effect of condition type on sameness judgments, $F(3,54)=36.1, p<.001$, showing that participants judged mismatch conditions less similar than match conditions. The interaction between condition type and proficiency was also significant $F(6,54)=2.3, p=.040$, suggesting that high proficiency bilinguals judged mismatch conditions to be less similar than match conditions.

Pairwise comparisons between conditions showed that Turkish-English bilinguals processed TPO-TPO pairs and TDO-TDO pairs indistinguishably. However, in mismatch conditions, participants found DO final pairs more similar than PO final pairs in Turkish $(M D=14.2, S E=3.8, p=.009)$. Unlike the first experiment, Turkish-English bilinguals have no difficulties processing DO sentences; in fact, they favour DO pairs. The following figure shows the differences between match and mismatch conditions across 
the three proficiency levels.

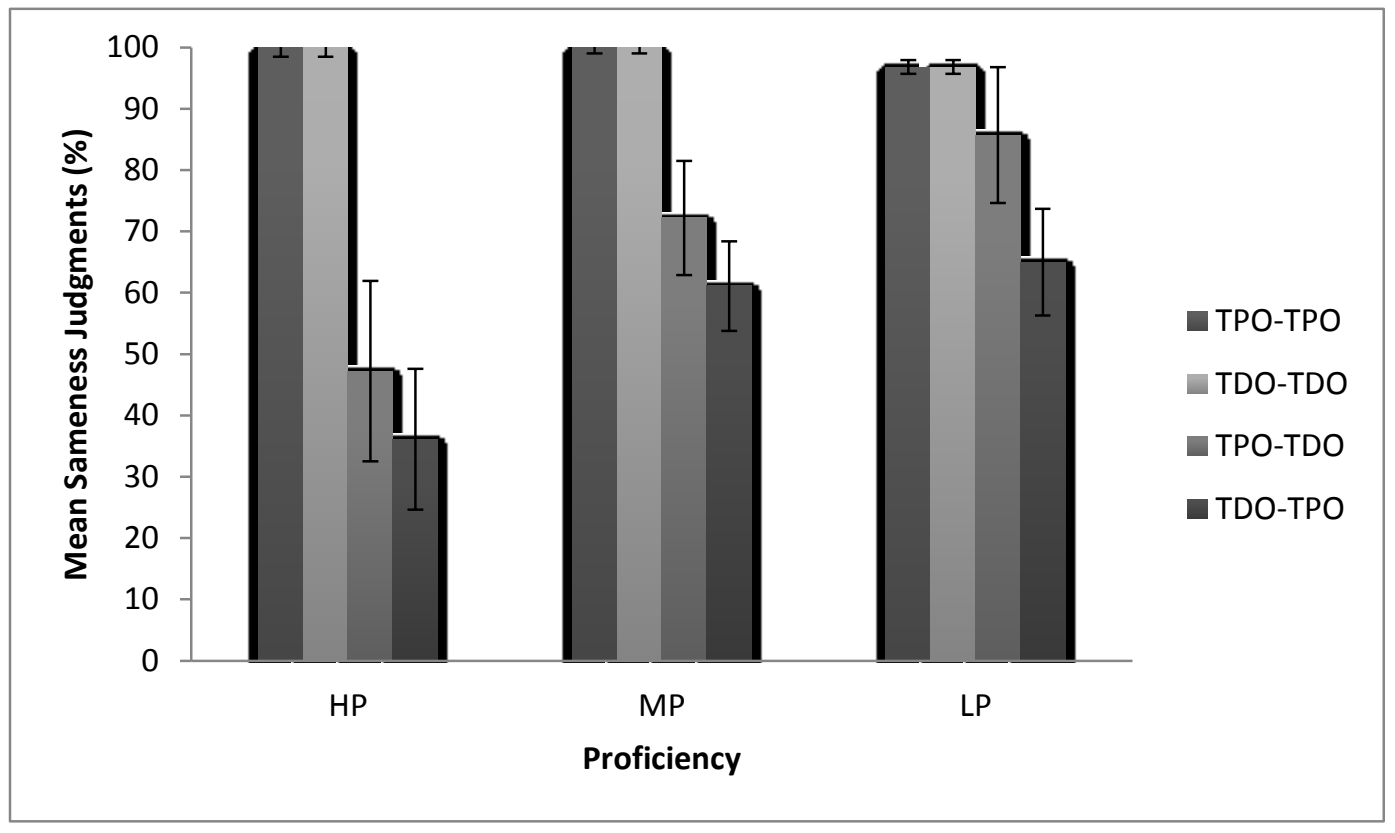

Figure 6 Sameness Judgments (\%) for Each Condition by Proficiency in Experiment 2 (within Turkish)

These results show that Turkish-English bilinguals found mismatch pairs to be less similar than match conditions, as they did in the first experiment, even though Turkish does not have syntactic differences between PO and DO sentences (except a word order variation). This suggests that their L2 proficiency affects their L1 knowledge.

\subsubsection{Reaction Times}

Mixed ANOVAs were conducted to compare the effect of condition (match and mismatch) on reaction times (RTs) within Turkish. Proficiency level was used as a between subject factor. There was a trend toward an effect of condition type on RTs, $F(3$, $54)=1.3, p=.279$. Participants reacted to Turkish match PO and DO sentences similarly, but when they had a mismatch condition, ending with a DO final pair (TPO-TDO), participants reacted slower to DO final mismatch pairs $(M D=248.7 \mathrm{~ms}, S E=92.3 \mathrm{~ms}, p=$ 
.015). Overall, Turkish-English bilinguals were more sensitive to DO sentences in Turkish.

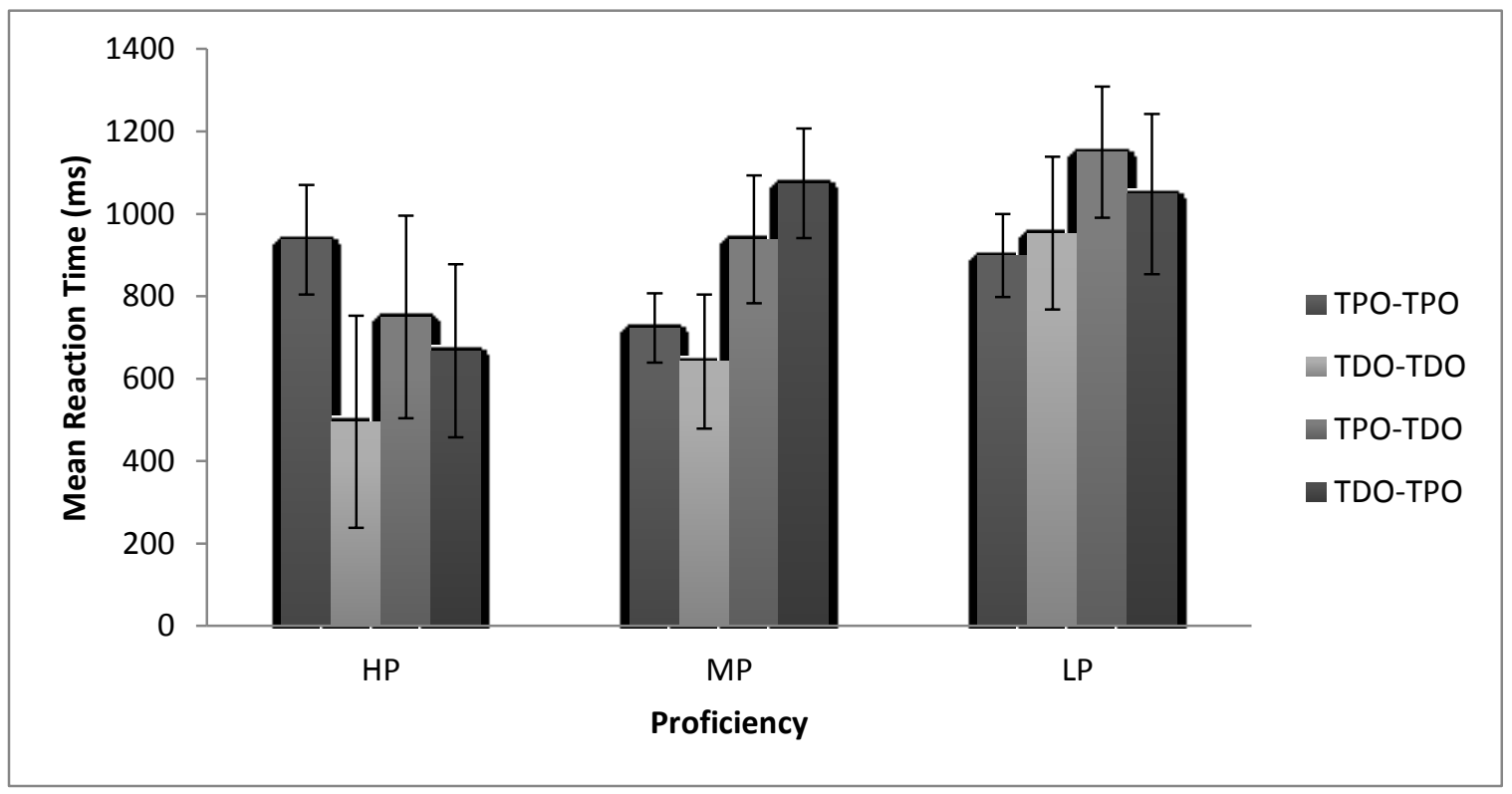

Figure 7 Reaction Times (ms) for Each Condition by Proficiency in Experiment 2 (within Turkish)

\subsection{Results for Experiment 3 (English-Turkish)}

Thirty-nine Turkish-English bilinguals in Turkey participated in this experiment. The high proficiency bilingual group had 11 participants, the mid proficiency bilingual group had 19 participants, and the low proficiency bilingual group had 9 participants. The participants' translation judgments (both correct and incorrect) and RTs were collected.

\subsubsection{Correctness Judgment}

Mixed ANOVAs were conducted to compare the effect of condition (match and mismatch) on correct translation judgments cross-linguistically (English-Turkish). Proficiency level was used as a between subject factor. There was a significant effect of condition type, $F(3,108)=8.1, p<.001$, showing that mismatch conditions were judged 
to be less correct than match conditions, as predicted (although only for the high proficiency group). There was no interaction between condition type and proficiency ( $F$ $(6,108)=.51, p=.794)$.

Pairwise comparisons between conditions showed that when Turkish-English bilinguals heard a mismatch condition (EPO-TDO or EDO-TPO), they judged more of the DO final pairs to be correct compared to PO final pairs $(M D=-9.9, S E=3, p=$ .013). This supports the previous results from Experiment 2, which demonstrate that when Turkish-English bilinguals hear a DO final sentence in Turkish, they prefer it. Overall, participants did not perform as accurately in this experiment as they did in the within language experiments. This is expected; it can be interpreted as the effect of the translation task. Since the translation task is a bilingual task, it requires processing in both languages. Although participants similarly judged match and mismatch conditions crosslinguistically, they show a similar pattern as in Experiment 2 by favouring DO final sentences in Turkish. The figure below shows how similarly the three proficiency groups performed in the translation task. 


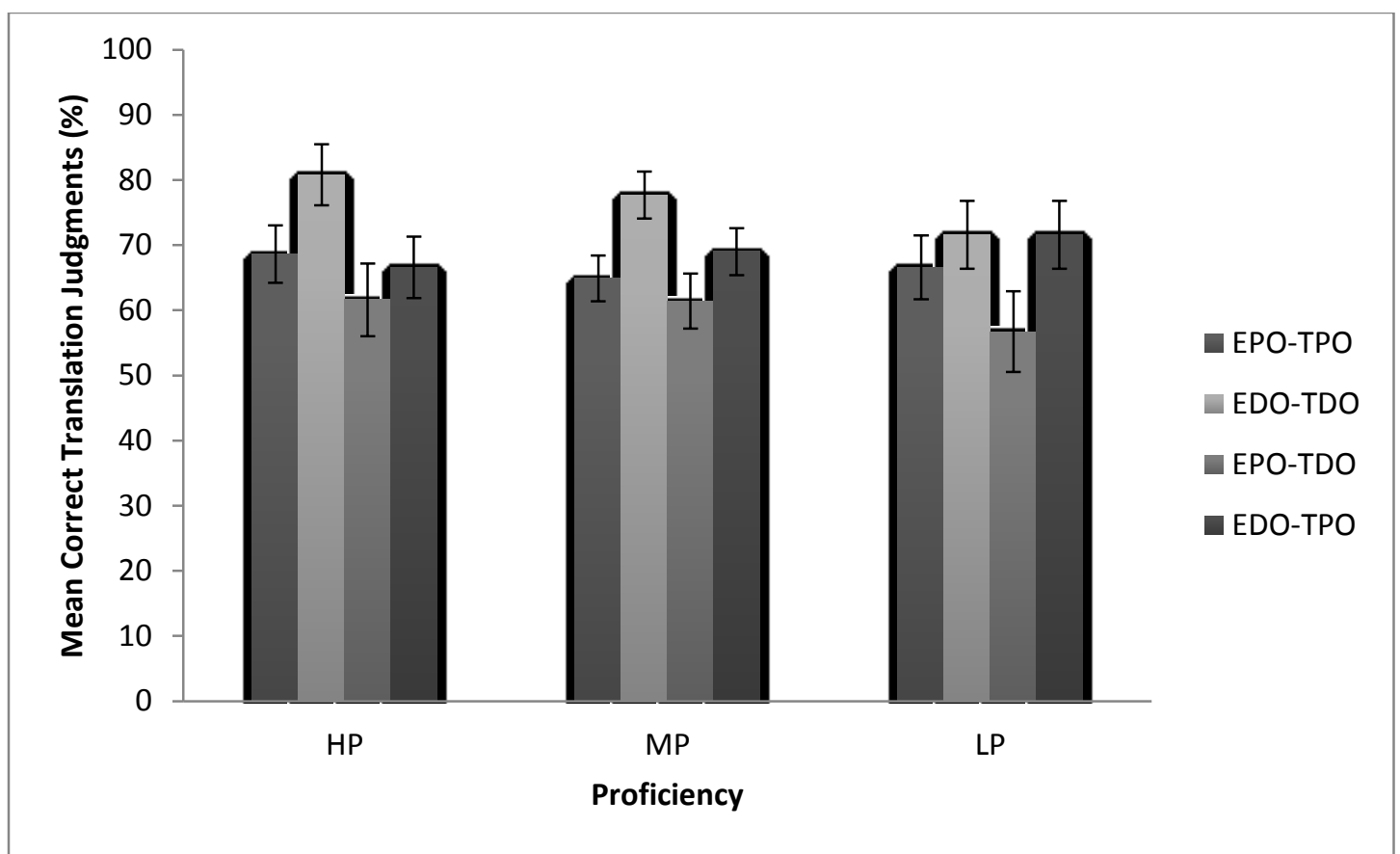

Figure 8 Correct Translation (\%) Judgments for Each Condition by Proficiency in Experiment 3 (English-Turkish )

\subsubsection{Reaction Times}

Mixed ANOVAs were conducted to compare the effect of conditions (match and mismatch) on reaction times (RTs) cross-linguistically (English-Turkish). Proficiency level was used as a between subject factor. There was no significant effect of condition type, $F(3,108)=.719, p=.543$. Since this test was a translation task, participants reacted to PO and DO sentences similarly. The variance for the EPO-TDO condition was large, which suggests that participants reacted slowly after they heard a marked sentence in English (EPO). Their decision took more time because Turkish does not mark PO and DO sentences overtly. 


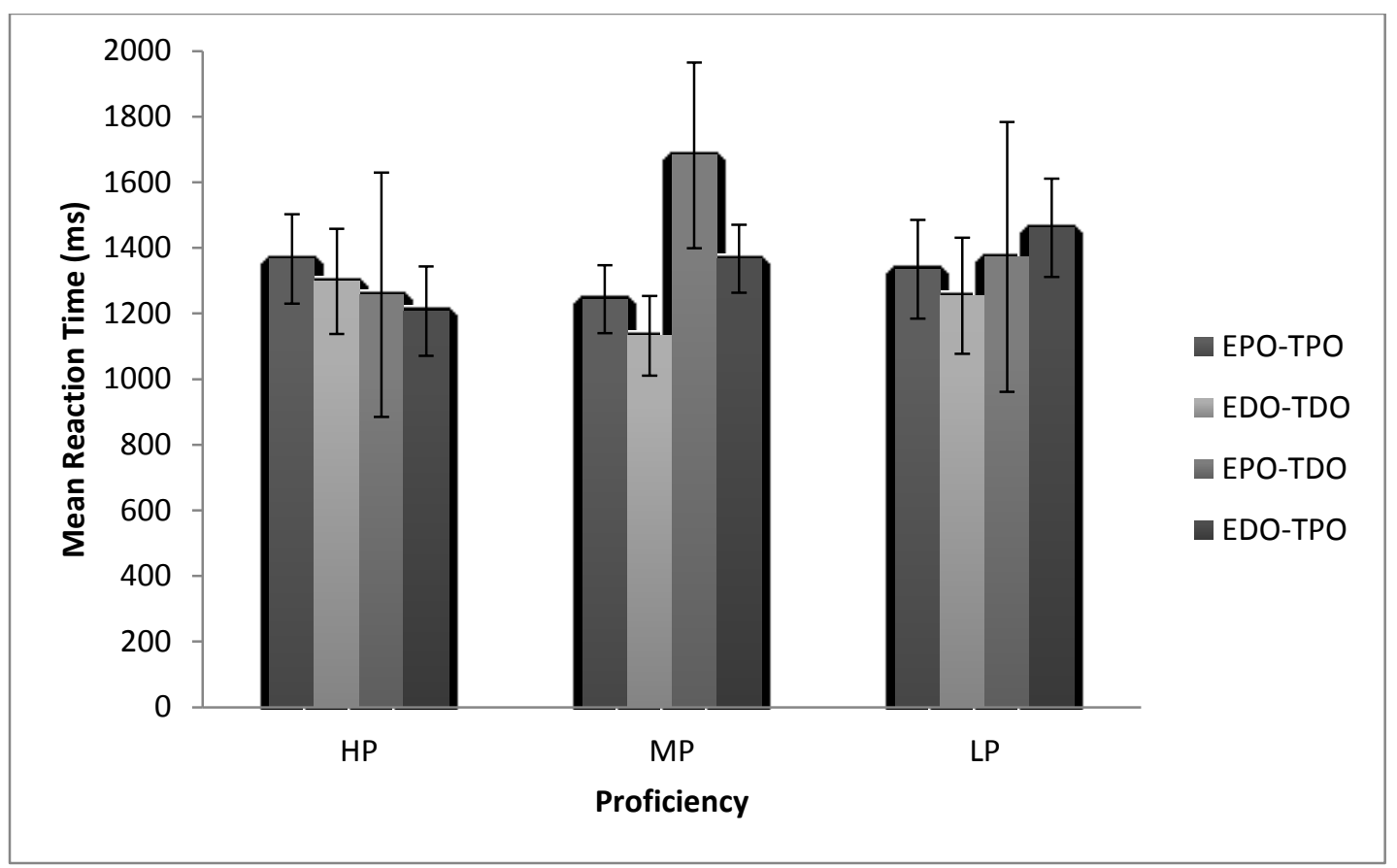

Figure 9 Reaction Times (ms) for Each Condition by Proficiency in Experiment 3 (English-Turkish)

\subsection{Results for Experiment 4 (Turkish-English)}

Thirty-eight Turkish-English bilinguals in Turkey participated in this experiment. The high proficiency bilingual group had 11 participants, the MP bilingual group had 18 participants, and low proficiency bilingual group had 9 participants. Participants’ translation judgments (both correct and incorrect) and RTs were collected.

\subsubsection{Correctness Judgment}

Mixed ANOVAs were conducted to compare the effect of condition (match and mismatch) on correct translation judgments cross-linguistically (Turkish-English). Proficiency level was used as a between subject factor. There was a significant effect of condition type, $F(2.3,80)=6.6, p<.001$, showing that participants judged more mismatched pairs to be the incorrect translation than matched pairs. There was no effect 
of proficiency as a between subject factor on the conditions $(F(2,35)=.455, p=.638)$. This partially supports our prediction that only high proficiency bilinguals would judge the mismatched pairs to be a more incorrect translation.

Pairwise comparisons between conditions showed that when Turkish-English bilinguals heard a mismatch condition (TPO-EDO or TDO-EPO), they judged DO final pairs more correct than PO final pairs $(M D=11.9, S E=3, p=.002)$. This shows that Turkish-English bilinguals showed sensitivity to English DO sentences. This suggests that during the translation task, Turkish-English bilinguals preferred DO word orders cross-linguistically. However, this did not happen in Experiment 1 (English-English), because in Experiment 1, Turkish-English bilinguals had difficulty in processing EDO sentences. This can be related to the word order similarity between DO sentences in English to PO and DO sentences in Turkish (i.e., they prefer a translation without prepositions). However, when participants heard a TDO-EPO, they did not judge them as correct translations because EPO is different from Turkish PO and DO sentences in terms of word order and structure (i.e., EPO contains an extra prepositional phrase).

\subsubsection{Reaction Times}

Mixed ANOVAs were conducted to compare the effect of condition (match and mismatch) on the reaction times (RTs) cross-linguistically (Turkish-English). Proficiency level was used as a between subject factor. There was a significant effect of condition type on RTs, $F(2.3,80)=8.7, p<.001$, showing that match conditions were judged faster than mismatch conditions. Unlike Experiment 3, participants had RT differences this time. The interaction between the condition type and proficiency was also significant 
$F(4.5,80)=1.9, p<.001$. Pairwise comparisons showed that participants reacted to TPO-EPO sentences faster than TDO-EDO sentences $(M D=140.8 \mathrm{~ms}, S E=68.1, p=$ .046). This further demonstrates that Turkish-English bilinguals were not as familiar with DO sentences in English. Overall, high proficiency bilinguals $(M=898 \mathrm{~ms}, S E=103 \mathrm{~ms})$ were slightly faster than mid proficiency $(M=1006.3 \mathrm{~ms}, S E=80.6 \mathrm{~ms})$ and low proficiency $(M=1159.7 \mathrm{~ms}, S E=114 \mathrm{~ms})$ participants.

\subsection{Overall Results}

Results from all four experiments suggest that Turkish-English bilinguals have different interpretations of PO and DO sentences depending on their proficiency levels. In Experiment 1 while high proficiency bilinguals were able to distinguish the syntactic differences between PO and DO sentences in English, and therefore interpreted the given question correctly, mid and low proficiency bilinguals could not. Instead, mid and low proficiency bilinguals focused on semantic and word order similarities within the English experiment. The high proficiency bilinguals' data looked similar to the data from the control group, because native speakers of English were also split into two, according to the question that they were given. When the native speakers' syntactic judgments were blocked by the question 'Do the two sentences have the same meaning?', they behaved like mid and low proficiency bilinguals. However, when their syntactic judgments were not blocked, and they were asked the same question as the experimental group ('Are these two sentences the same?'), they behaved like high proficiency bilinguals.

For Experiment 2 (within-Turkish), high proficiency bilinguals were able to distinguish between PO and DO sentences to some extent, whereas mid and low 
proficiency bilinguals were not able to distinguish the word order differences between PO and DO sentences. RTs showed that match conditions (i.e., PO-PO or DO-DO) were faster to process than mismatch conditions (i.e., PO-DO or DO-PO). The data also show that DO sentences were faster to be processed when compared to PO sentences within languages. The results from Experiment 1 and Experiment 2 suggest that high proficiency Turkish-English bilinguals can have a shared syntax for English and Turkish because they can differentiate PO and DO sentences cross-linguistically. Although PO and DO sentences do not have an overt syntactic difference in Turkish, they have different word order and focus position so high proficiency Turkish-English bilinguals' English knowledge is shared with Turkish, which led them to the right interpretation of these two sentence types. However, mid and low proficiency participants (purposefully) focus on the semantics of the PO and DO sentences cross-linguistically, which suggests that they do not have a shared syntax.

In Experiments 3 and 4, the translation tasks, there was no difference between English to Turkish and Turkish to English. Correctness judgments were similar across all conditions. Although high proficiency bilinguals reacted to some of the PO-DO differences, it was not significant. RTs were slower compared to Experiment 1 and Experiment 2, likely because Experiments 3 and 4 included an additional task: translation. Therefore, participants had to decide on more than the correctness of the target sentences; they also checked the grammaticality of the prime and the target sentences, alongside their meaning. Participants were confused as to whether the target sentence was a good translation of the prime sentence because English syntactically distinguishes PO and DO structures, whereas Turkish does not, and even allows for free 
word order. However, high proficiency bilinguals showed sensitivity to word order crosslinguistically. For instance, they mostly found the TDO sentence to be the correct translation of the EDO prime sentence, whereas they found the TPO sentence to be the correct translation of the EPO sentence less frequently. Overall, Turkish-English bilinguals quickly reacted to the DO sentences in Turkish and the PO sentences in English. This can be explained by structural marking: English marks PO structures with a preposition, so it is easier for speakers to recognize it. On the other hand, in Turkish, the case-marking shows no differences for PO and DO structures. The word order, however, does; as a result, when Turkish-English bilinguals had a mismatch condition, they found Turkish DO sentences more similar (Experiments 1 and 2) or more correct (Experiments 3 and 4). This shows that animacy can play a role on the preference of PO or DO order in Turkish. Although, in Chapter 3, it had been shown that Turkish allows both animate and inanimate objects for ditransitive verbs, the data shows that Turkish-English bilinguals prefer DO orders over PO orders because DO order has the animate-inanimate order of objects, whereas PO order has inanimate-animate objects. Thus, Turkish-English bilinguals may have DO word order as the default structure, and they may be changing the focus of the sentence (i.e., using PO structure to make an emphasis on the indirect object) according to their goal (for the comparisons of the four experiments see Appendix C).

Overall, participants reacted very similarly in Experiment 3 (English-Turkish) and in Experiment 4 (Turkish-English), which supports the hypotheses that when two languages are both active, the decision about $\mathrm{PO}$ and DO sentences is harder. Although the translation data does not show clearly whether Turkish-English bilinguals have a 
shared syntax, it suggests that there are some cognitive mechanisms such as animacy that enable them to follow the differences between PO and DO sentences. 


\section{Chapter: Discussion and Future Directions}

The shared syntax account suggests an underlying common syntactic system for more than one language. Previously, syntactic priming studies showed that typologically related languages mostly share syntactic information. Therefore, the shared syntax account entails a typological advantage for bilinguals of typologically similar languages (i.e., English-Spanish, English-French, Spanish-French, French-Italian). However, bilingualism can happen between any types of languages, and if our hypothetical shared syntax cannot account for typologically different languages, then it will be interesting to see what changes occur in the brain of bilinguals, who speak typologically dissimilar languages. Is there any epistemological difference between typologically similar bilinguals and typologically dissimilar bilinguals or is it a matter of empirical design that fails to show it?

In this regard, this study aimed at showing whether Turkish and English bilinguals, speakers of two typologically different languages, are able to create a shared syntax for PO and DO sentences, structures that are syntactically (including word order variations) different from each other in both languages. Instead of testing general Turkish-English bilinguals in Turkey due to the low proficiency in the country, a specific group of bilinguals that are known for their high proficiency, simultaneous interpretation students, was tested. In this study, some ditransitive verbs, which can be used both with PO and DO structures in English, and their Turkish equivalents were used. While English has two distinct structures for PO and DO sentences, Turkish has only one structure but two different word orders. 
For Experiment 1, I hypothesized that match conditions will be judged to be the same across all proficiency groups, whereas, mismatch conditions can be judged to be the same or different depending on the proficiency level. For mismatch conditions, I anticipated seeing 'different' judgments only from high proficiency bilinguals. The results of Experiment 1 upheld this hypothesis. High proficiency simultaneous interpretation students distinguish PO and DO structures in English, whereas mid and low proficiency simultaneous interpretation students were not able to distinguish syntactic differences between PO and DO sentences. This supports my hypothesis that the high proficiency bilinguals can have a shared syntax. Moreover, the control group was split into two by means of two different questions. Results showed that when native speakers of English were asked whether a PO-DO pair or DO-PO pair sentence was the same or not, they judged the PO-DO and DO-PO pairs as different. This result overlaps with the high proficiency bilinguals in the experimental group. To observe whether mid proficiency and low proficiency bilinguals used only world knowledge (i.e., pragmatics) to separate PO-DO pair sentences, half of the control group was asked whether a PO-DO pair sentence had the same meaning or not. Native speakers of English judged such pairs as having the same meaning. Thus, these results overlap with Turkish-English mid and low bilinguals' judgments. This shows that native-like processing involve a syntactic and semantic layer, and high proficiency Turkish-English bilinguals have these two layers, whereas mid and low proficiency Turkish-English bilinguals have one layer (i.e., semantics) rather than two layers (i.e., syntactic and semantic). One can conclude that the results from Experiment 1 support the idea that proficiency can play a role in shared syntax. Apart from the syntactic and semantic processes, participants' interpretation of 
the given question was of interest for this study. The results showed that high proficiency bilinguals interpreted the question "Are they the same?" by means of structural difference, whereas mid and low proficiency participants interpreted the same question by means of semantic similarity. This difference between the two interpretations can be further investigated by using the same methodology with a working memory task, because high proficiency bilinguals may have a different working memory that enables them to follow the structural (i.e., word order) differences, but mid and low proficiency bilinguals may not have the same working memory, and that may be the reason why they may have purposefully chosen the semantic similarity.

For Experiment 2, I anticipated seeing similar patterns to Experiment 1. I hypothesized that if participants judge the mismatch conditions to be different, it will show that their L2 knowledge interacts with their L1 knowledge. The results of Experiment 2 showed that all Turkish-English bilinguals behaved similarly in Experiment 2 as they did in Experiment 1 (e.g., high proficiency bilinguals judged PO-DO and DOPO pairs as different, mid and low proficiency bilinguals judged PO-DO and DO-PO pairs as the same). These results upheld my hypothesis that $\mathrm{L} 2$ knowledge can interact with L1 knowledge as previously suggested by Brien (2013). Moreover, being a high proficiency bilingual may have helped Turkish-English bilinguals to follow the word order change in Turkish (i.e., working memory). Overall, both Experiment 1 and Experiment 2 show that high proficiency Turkish-English bilinguals were able to create a shared syntax or an interaction between English and Turkish, whereas mid proficiency participants started to develop it, and low proficiency participants did not have it. 
As for RT, for Experiments 1 and 2, I anticipated differences in RTs between high and low proficiency groups. I also anticipated seeing faster RTs for PO sentences in English, since DO sentences are taught after PO sentences in EFL in Turkey. I anticipated seeing RT differences for Turkish PO and DO structures, if participants have a preferred structure in Turkish as an underlying form.

In Experiment 1 (English-English), participants seemed to process PO sentences quicker than DO sentences, and in Experiment 2 (Turkish-Turkish), they seemed to process DO sentences quicker than PO sentences. These results support my hypothesis in terms of favoured structures cross-linguistically. Since Turkish-English bilinguals acquired PO structure before DO (i.e., frequency effect), they processed PO structures faster and more accurately. In terms of favouring DO structures in Turkish, one could look at the order of the animate and inanimate objects. The results showed that TurkishEnglish bilinguals judged DO final pairs in mismatch conditions more similar than PO sentences in Turkish. As I discussed earlier, Turkish allows both animate and inanimate objects in DO and PO sentences (see Chapter 3). However, in this study, Turkish-English bilinguals showed a preference for DO sentences in Turkish, meaning that they tend to put animate object before the inanimate object. This has been shown in the previous literature (Bresnan et al. 2001; Verhoeven, 2014). The previous corpus studies on crosslinguistic analysis showed that animate objects are placed before the inanimate objects. In a cross-linguistic (German, Greek, Turkish, and Chinese) production study, Verhoeven (2014) showed that speakers of German, Greek, Turkish, and Chinese (all typologically dissimilar) put animate objects higher in the sentence structures. 
Experiment 3 (English-Turkish) and Experiment 4 (Turkish-English) showed that the correct translation judgment was a challenge for simultaneous interpretation students. Since PO and DO sentences are very similar in Turkish, and DO sentences in English are hard to process, participants may have had problems distinguishing PO and DO sentences. However, this does not mean that they do not have a shared syntax; this may be related to the activation problem in translation. Since translators have to keep both of the languages active, whereas bilinguals do not have to, translators may show different processing compared to bilinguals (Paradis, 1994). However, for future directions, heritage speakers' code-switching ${ }^{18}$ can be investigated to see whether the shared syntax is affected by the activation of more than one language.

Overall, results also show that high proficiency bilinguals have a greater awareness of word order variation such that they could recognize the word order differences in PO and DO sentences in English, and they also show a tendency towards recognizing these variations in Turkish (especially high proficiency bilinguals), which is hard to distinguish when compared to English. This recognition also suggests that the high proficiency speakers were able to access information about higher-level syntactic processes, such as focus. Focus can be one of the factors that may affect the PO-DO variation cross-linguistically. For instance, Turkish speakers tend to put focus before the verb as Turkish is a verb final language, and the object that comes right before the verb has the focus of the sentence (Erguvanli Taylan, 1984, p. 34). In this case, when a Turkish native speaker would like to emphasize the beneficiary instead of the object, they may prefer to use the PO word order in Turkish (e.g., Ali the flowers ACC Ayse-yedaT

\footnotetext{
${ }^{18}$ Code-switching: the act of alternating languages that happens in bilingual or multilingual populations.
} 
gave.). In contrast, mid and low proficiency bilinguals could only share the global meaning of sentences within and between languages, and they could not distinguish syntactic nuances, such as focus and word order variations. Further research can be done to see how Turkish speakers differentiate between focus and the animacy effect. For instance, do they prefer to put inanimate objects before the focus position?

Crucially, this study shows that while high proficiency bilinguals were sensitive to higher-level syntactic processes within and between languages, mid and low proficiency bilinguals did not show this effect. This can show that high proficiency bilinguals could be aware of differences in their first and second languages. Future research can be done to show whether this awareness is due to their working memory or not.

The goal of this study was to extend the shared syntax account from typologically similar languages to typologically dissimilar languages. This study took shared syntax as successfully assigned and process information between typologically dissimilar languages, the results suggest that high proficiency Turkish-English bilinguals successfully assign PO and DO sentences in Experiment 1 and Experiment 2, which suggests a shared syntax for them. Because of the extra load of the translation task, this was not observed in Experiments 3 and 4; however, participants showed a preference for Turkish DO sentences and English PO sentences across all experiments. It can be deduced that Turkish-English bilinguals have an underlying structure that is DO word order, and this order can be related to an animacy effect but they also have a wellacquired knowledge of PO sentences for English. Therefore, Turkish-English bilinguals, especially high proficiency ones, have a shared knowledge of PO and DO structures (i.e., 
a shared animacy effect) cross-linguistically. However, further research is needed to replicate the same results with a production-based study.

Previous studies with monolingual sentence processing showed that structural predictions are fast, and an elicited (E)LAN ${ }^{19}$ effect can show this prediction process (Lau et al., 2006). However, there has not been much emphasis on how second language learners or bilinguals can reach the predictive level during sentence processing. This study showed that Turkish-English bilinguals were fast to react to PO and DO sentences. For future studies, this research can be the baseline for the factors that enable or enhance automaticity in sentence processing. For instance, for simultaneous interpretation students, a change in their manner of acquisition, such as becoming ESL speakers instead of EFL, could enhance their proficiency level; therefore, they could start to gain automaticity in second language processing or due to their training, simultaneous interpretation students may start to develop different working memory. Also, more work is needed to understand how simultaneous interpreters process different languages quickly and precisely.

Further investigations with EEGs (electroencephalography) can be done to observe (E)LAN effects for automaticity in high proficiency bilinguals. Although, behaviourally, high proficiency bilinguals can show native-like processes, temporally, they may or may not be able to show automaticity. Also, the animacy effect in Turkish can be compared to other languages to see whether a change in word order is related to

\footnotetext{
${ }^{19}$ The early left anterior negativity (ELAN) is an event-related potential in electroencephalography (EEG). This specific brain activity happens when there is a negative-going wave that peaks around 200 milliseconds after the onset of a stimulus. For instance, a violation of phrase structure rules or the category of the word can create an ELAN effect (e.g., the for charity).
} 
animacy or not. As a result of this, the theoretical works on PO and DO sentences may also have an empirical ground.

To conclude, this research was the first but will not be the last to investigate the shared syntax account from typologically unrelated languages by testing simultaneous interpreters. More research is needed to understand typologically different languages and how bilinguals of these languages achieve processing differences between their languages. The main goal of this study was to propose a different methodology to test typologically different languages. From this point onwards, the crucial questions for future studies are: what has changed in the language faculty and the working memory of high proficiency bilinguals that enables them to interpret the sameness question in terms of structural differences between PO and DO sentences, and what is in the language faculty and the cognitive process that inhibits mid proficiency and low proficiency bilinguals from structurally differentiating PO and DO sentences? 


\section{Appendices}

\section{Appendix A ISPR Announcement}

We are looking for native English speakers to participate in a 45 minutes study about how English grammar affects your thinking. You will begin by filling out a short questionnaire and then begin the task. The task is simple and quick. It consists of responding to easy sentences in English by pressing a button. If your second language is French, please contact the researcher before signing up. Thank you for your interest in our study, and we look forward to seeing you in the Brain and Language Lab (ARTS 408)! 


\section{Appendix B Consent Form}

The purpose of this informed consent form is to ensure that you understand both the purpose of the study and the nature of your participation. The informed consent must provide you with sufficient information so that you have an opportunity to determine whether you wish to participate in the study. Please read this form carefully and ask any questions you may have before consenting to participate in the study.

\section{Study Title}

Language Processing during Simultaneous Interpretation between Turkish and English

\section{Purpose}

The purpose of this study is to investigate the human cognitive and information (language) processing system by examining how English and Turkish speakers are processing sentences. This study makes use behavioural measures.

The study is designed to answer some basic questions about the relation between the brain and behaviour and should in no way be perceived as therapy, nor will it benefit the participant directly.

\section{Task Requirements}

If you are a native Canadian speaker or a native Turkish speaker, in this study you will be asked to perform one behavioural task. During the behavioural task you will be instructed to listen to a sentence, and following you will hear another sentence. After you hear the second sentence, you will be asked to answer a question about the sentence you have just listened to whether the two sentences match by using a response pad.

If you are a Turkish-English bilingual, in this study you will be asked to perform two behavioural tasks. During the behavioural tasks you will be instructed to listen to a sentence, and following you will hear another sentence. After you hear the second sentence, you will be asked to answer a question about the sentence you have just listened to whether the two sentences match by using a response pad. Following the first experiment, you will hear a sentence in English or in Turkish, and then you will hear a translation sentence in the opposite language, and you will be asked to decide whether the translation is correct or not.

\section{Eligibility Requirements}

The study requires right-handed Canadian English speakers, Turkish native speakers, and Turkish-English bilinguals between the ages of 18 and 35 with good or corrected vision (with soft contact lenses or glasses), without speech or hearing impairments, who have not been diagnosed with any neurological disorders. Canadian participants who were exposed significantly to any languages other than English, and Turkish-English bilingual participants who were exposed to any other languages other than Turkish and English significantly will be excluded from the study. 


\section{Duration and Locale}

The study will take place in the Brain and Language Laboratory (408 Art Building, University of Ottawa) and will last approximately 45 minutes, including instructions and debriefing.

\section{Remuneration}

You will be thanked (For Turkish-English Bilinguals)/You will receive 1 point. (For

ISPR Students)

\section{Potential Risk or Discomfort}

There are no known risks associated with the behavioural part of this study.

\section{Anonymity and Confidentiality}

Any personal information you provide will be kept confidential, and any data collected in the study will be coded with random numbers so that the data remain anonymous. Only the research personnel involved in this study will have access to the data.

\section{Data Security and Management}

Any data collected in the study (e.g., filled out questionnaires, electronic files) will be either kept in a locked cabinet or stored in a password protected computer or hard drive in the Brain and Language Laboratory (408 Art Building, University of Ottawa). All the data will be destroyed within ten years after the completion of the study.

\section{Right to Withdraw}

If at any point you wish to terminate your participation you may do so without any penalty and without

being asked for a reason. You will receive you compensation even if you choose to

withdraw from the study.

\section{Contact information}

For questions about this study, please contact:

Ayşegül Kutlu, Principal investigator

(email: aysegulkutlu@cmail.carleton.ca, phone: 613-520-2600 ext. 3268)

Dr. Kumiko Murasugi, Primary faculty sponsor

(email: kumiko_murasugi@carleton.ca,phone: 613-520-2600, ext. 2197)

Dr. Laura Sabourin, Co-supervisor

(email: laura.sabourin@uottawa.ca, phone: 613-562-5800, ext. 1763)

For any other concerns related to please contact the University of Ottawa Ethics Office at ethics@uottawa.ca at 613-562-5387 or REB chair at Carleton University, Professor Andy Adler at ethics@,carleton.ca or at 613-520-2517

For any other concerns, please contact: 
Dr. Jo-Anne LeFevre, Director, Institute of Cognitive Science (email: joanne.lefevre@carleton.ca,

phone: 613-520-2600 ext. 2693).

This study has been approved by the Carleton University (Study Number \#101222) and University of Ottawa Ethics Committee (03-14-10).

\section{Statement of consent}

I acknowledge that my participation in this research project is voluntary. I have read the above information and the study has been explained to my satisfaction. I understand that I have the right to withdraw from the study at any time and that my identity will be kept confidential and will not be associated with any of the information/data I provide. I also know that my withdrawal will not affect my compensation reception. There are two copies of the form, the researcher and I signed both of them, I will keep one copy of the form, and the researcher will keep the other copy. My signature indicates that I consent to participate in the experiment.

Print your name

Researcher's name

Signature

Researcher's signature

Date

Date 


\section{Appendix C}

Summary of Statistical Results for Turkish Participants across Experiments $(n \mathrm{~s}=21,21$, 39 and 38, respectively).

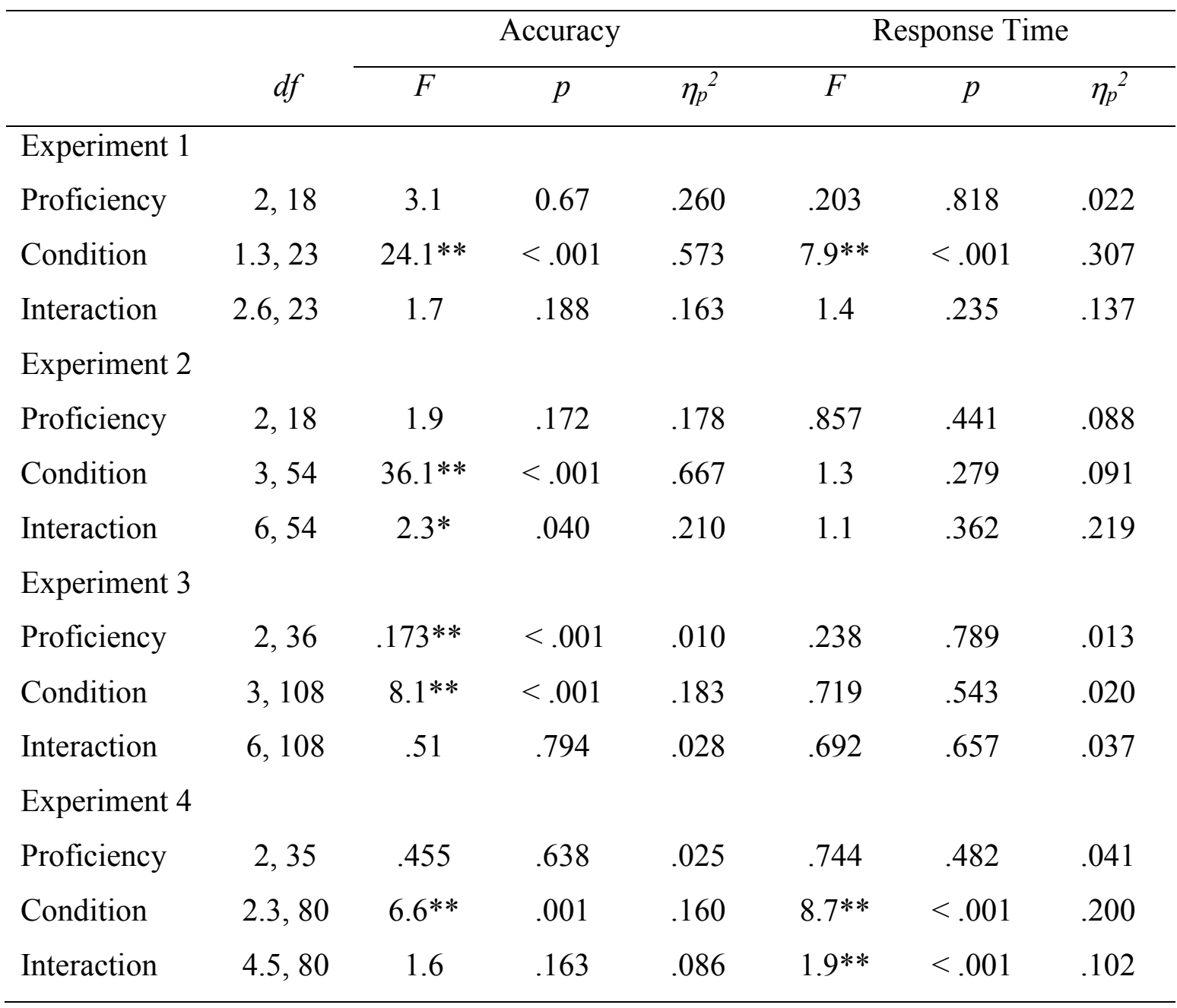

$* \mathrm{p}<.05 ; * * \mathrm{p}<.01$ 


\section{References}

Abutalebi, J., \& Weekes, B. S. (2014). The Cognitive Neurology of Bilingualism in the Age of Globalization. Behavioural Neurology, 2014, 1-3.

Baker, C. (1988). Key Issues in Bilingualism and Bilingual Education. Clevedon, UK: Multilingual Matters.

Beck, S., \& Johnson, K. (2004). Double Objects Again. Linguistic Inquiry, 35(1), 97123.

Bernolet, S., Hartsuiker, R., \& Pickering, M. (2007). Shared syntactic representations in bilinguals: Evidence for the role of word-order repetition. Journal of Experimental Psychology: Learning, Memory, and Cognition, 33, 931-949

Bock, J. K. (1986). Syntactic persistence in language production. Cognitive Psychology, $18,355-387$.

Bosch, L., \& Sebastián-Gallés, N. (2001). Evidence of Early Language Discrimination Abilities in Infants From Bilingual Environments. Infancy, 2(1), 29-49. 
de Bot, K. (1992) A Bilingual Processing Model: Levelt's 'Speaking’ Model Adapted. Applied Linguistics, 13: 1-24.

Branigan, H., Pickering, M., \& Cleland, A. (2000). Syntactic co-ordination in dialogue. Cognition, 75, B13-B25.

Branigan, H., Pickering, M., McLean, J. F., \& Cleland, A.(2007). Syntactic alignment and participant role in dialogue. Cognition, 104, 163-197.

Bresnan, J. (1978). A Realistic Transformational Grammar. In M. Halle, J. Bresnan, G. M. contributors, \& J. B. . . [et al.], Linguistic theory and psychological reality. United States: Cambridge, Mass. : MIT Press, c1978.

Bresnan, J., Cueni, A., Nikitina, T., \& Baayen, H. (2007). Predicting the Dative Alternation. In G. Bouma, I. Kramer, \& J. Zwarts, Cognitive Foundations of Interpretation (Verhandelingen, Afd. Letterkunde, Nieuwe Reeks). Netherlands: Edita-the Publishing House of the Royal.

Brien, C., \& Sabourin, L. (2012). Second language effects on ambiguity resolution in the first language. EUROSLA Yearbook, 12, 191-217.

Brien, C. (2013). Neurophysiological evidence of a second language influencing lexical ambiguity resolution in the first language. Ph.D Thesis. 
Bruening, B. (2010). Double Object Constructions Disguised as Prepositional Datives. Linguistic Inquiry, 41-2.

Bruening, B. (2012, August 30). R-Dative Shift Revisited: Reply to Ormazabal and Romero. Retrieved from http://udel.edu/ bruening/Downloads/RDativeRevisited1.pdf

Butler, Y.G. (1996). Introduction. In G. Brown, K. Malmkjaer, J. Williams (eds.), Performance and Competence in Second Language Acquisition, 1-8. Cambridge, UK: Cambridge University Press.

Butler, Y.G. (2000). The age effect in second language acquisition: Is it too late to acquire native level competence in a second language after the age of seven? In Y. Oshima Takane, Y. Shirai, and H. Shirai (eds.), Studies in Language Sciences, $1,159-169$.

Campbell, C. \& Ortiz, J. (1991). Helping students overcome foreign language anxiety: a foreign language anxiety workshop. In E.K. Horwitz \& D.J. Young, (Eds.). Language Anxiety: From Theory and Research to Classroom Implications. Englewood Cliffs, NJ: Prentice Hall. 153-168. 
Carruthers, P. (2006). The Case for Massively Modular Models of Mind. In R. Stainton, Contemporary debates in cognitive science. United Kingdom: Wiley, John \& Sons, Incorporated.

Chersi, F. (2012). Learning Through Imitation: a Biological Approach to Robotics. IEEE transactions on autonomous mental development. 4-3.

Chomsky, N. (1955). Logical Syntax and Semantics: Their Linguistic Relevance. Language, 31(1), 36-45.

Chomsky, N., \& Skinner, B. (1959). Verbal behavior by B. F. Skinner. Language, 35(1), $26-58$.

Chomsky. (1965). Persistent Topics in Linguistic Theory. Diogenes, 13(51), 13-20.

Christoffels, I., De Groot, A., \& Kroll, J. (2006). Memory and language skills in simultaneous interpreters: The role of expertise and language proficiency. Journal of Memory and Language, 54, 324-345.

Christoffels, I., \& De Groot, A. (2004). Components of simultaneous interpreting: Comparing interpreting with shadowing and paraphrasing. Bilingualism: Language and Cognition, 7 (3), 227-240. 
Cleland, A. A., \& Pickering, M. J. (2003). The use of lexical and syntactic information in language production: Evidence from the priming of noun-phrase structure. Journal of Memory and Language, 49, 214-230.

Crain, S., \& Thornton, R. (1998). Investigations in Universal Grammar: A Guide to Experiments on the Acquisition of Syntax and Semantics (1st ed.). United States: MIT Press.

Crystal, D. (2003). English as a Global Language. United Kingdom: Cambridge University Press (Virtual Publishing).

Çetinoglu, Ö. \& Butt, M. (2008). Turkish non-canonical objects. In M. Butt, \& T.H. Kings (Eds.), Proceedings of LFG08 Conference (pp. 214-234). Sydney, Australia. CSLI Publications.

Demiral, S. B., Schlesewsky, M., \& Bornkessel-Schlesewsky, I. (2008). On the universality of language comprehension strategies: Evidence from Turkish. Cognition, 106, 484-500.

De Houwer, A. (2006). The Acquisition of Two Languages from Birth: A Case Study. United Kingdom: Cambridge University Press. 
De Houwer, A. (2009). Bilingual first language acquisition. United Kingdom: Channel View Publications Ltd.

Döpke, S. (2000). Generation of and retraction from cross-linguistically motivated structures in bilingual first language acquisition. Bilingualism: Language and Cognition, 3(3), 209-226.

Dryer, M. (1986). Primary Objects, Secondary Objects, and Antidative. Language, 62(4), $808-845$.

Dulay, H., Burt, M., \& Krashen, S. (1982). Language Two. New York: Oxford University Press.

Edwards, J.V. (2004). Foundations of Bilingualism. The Handbook of Bilingualism edited by Bhatia T.K and Ritchie, W.C., Blackwell, 7-31.

Elmer, S., Meyer, M., \& Jancke, L. (2010). Simultaneous interpreters as a model for neuronal adaptation in the domain of language processing. Brain Research, 1317, $147-156$. 
Fedor, A., Ittzés, P., \& Szathmáry, E. (n.d.). The Biological Background of Syntax Evolution. In D. Bickerton \& E. Szathmary, Biological Foundations and Origin of Syntax. United Kingdom: MIT Press Ltd.

Felser, C., Marinis, T., \& Clahsen, H. (2003). Children's Processing of Ambiguous Sentences: A Study of Relative Clause Attachment. Language Acquisition, 11(3), $127-163$.

Felser, C., Roberts, L., Marinis, T., \& Gross, R. (2003). The processing of ambiguous sentences by first and second language learners of English. Applied Psycholinguistics, 24.

Flett, S., Branigan, H.P., \& Pickering, J. (2013). Are non-native structural preferences affected by native language preferences?. Bilingualism: Language and Cognition. $16,751-760$.

Frank, M. C., Everett, D. L., Fedorenko, E., \& Gibson, E. (2008). Number as a cognitive technology: Evidence from Pirahã language and cognition.Cognition, 108(3), 819-824.

García, A. M. (2012). Brain activity during translation: A review of the neuroimaging evidence as a testing ground for clinically-based hypotheses. Journal of Neuroscience, 26, 370-383. 
Garrod, S., \& Pickering, M. (2007). Alignment in dialogue. Oxford Handbooks Online.

Genesee, F. (1978). Is there an optimal age for starting second language instruction? McGill Journal of Education, 13, 145-154.

Gerver, D. (1976). Empirical studies of simultaneous interpretation: A review and a model. In R. W. Briskin (Ed.), Translation: Applications and research, 165-207. New York: Gardner Press.

Goldberg, A. (1995). Constructions: A Construction Grammar Approach to Argument Structure. United States: University of Chicago Press.

Green, D.W. (2011). Language control in different contexts: the behavioral ecology of bilinguals speakers. Frontiers in Psychology, 2:103, 1-4

Grosjean, F. (1998). Studying bilinguals: Methodological and conceptual issues. Bilingualism: Language and Cognition, 1(2), 131-149.

Güneş, B. (2009). 1945-1980 arası Türkiye'de Ingilizce Eğitimi (Unpublished PhD Thesis).

Hartsuiker, R. J., Kolk, H. H. J., \& Huiskamp, P. (1999). Priming word order in sentence production. Journal of Experimental Psychology, 52(A), 129-147. 
Hartsuiker, R. J., \& Westenberg, C. (2000). Word order priming in written and spoken sentence production. Cognition, 75, B27-B39.

Hartsuiker, R., Pickering, M., \& Veltkamp, E. (2004). Is Syntax Separate or Shared Between Languages? Psychological Science, 15(6), 409-414.

Hartsuiker, R., Bernolet, S., Schoonbaert, S., Speybroeck, S., \& Vanderelst, D. (2008). Syntactic priming persists while the lexical boost decays: Evidence from written and spoken dialogue. Journal of Memory and Language, 58, 214-238.

Kantola, L., \& Gompel, R. (2010). Between- and within-language priming is the same: Evidence for shared bilingual syntactic representations. Memory \& Cognition, 39(2), 276-290.

Lambert, S. (1992). Shadowing. Meta, 37, 263-273.

Larson, R. (1988). On the Double Object Construction. Linguistic Inquiry, 19-3.

Lau, E. (2009). The predictive nature of comprehension (Doctoral dissertation). University of Maryland. Retrieved from Carleton University Library. 
Lau, E., Stroud, C., Plesch, S., \& Phillips, C. (2006). The role of structural prediction in rapid syntactic analysis. Brain and Language, 98, 74-88.

Levelt, M., \& Kelter, S. (1982). Surface form and memory in question answering. Cognitive Psychology, 14, 78-106.

Lim, J. H., \& Christianson, K. (2012). Second language sentence processing in reading for comprehension and translation. Bilingualism: Language and Cognition, 16(03), 518-537.

Lingnau, A., \& Caramazza, A. (2014). The origin and function of mirror neurons: The missing link. Behavioral and Brain Sciences, 37(02), 209-210.

Loebell, H., \& Bock, K. (2003). Structural priming across languages. Linguistics, 41, $791-824$.

Lowenthal, K., Bull, D. (1984). Imitation of the foreign sounds: What is the effect of age? Language and Speech, 27, 95-7.

Marantz, A. (1993). A Late Note on Late Insertion. In Explorations in Generative Grammar. A Festschrift for Dong-Whee Yang. Hankuk Publishing Co. 
Meijer, P., \& Tree, J. F. (2003). Building Syntactic Structures in Speaking: A Bilingual Exploration. Experimental Psychology (formerly 'Zeitschrift Für Experimentelle Psychologie'), 50(3), 184-195.

Miyagawa, S., \& Tsujioka, T. (2004). Argument Structure and Ditransitive Verbs in Japanese. Journal of East Asian Linguistics, 13(1), 1-38.

Miyagawa, S. (2012). Case, argument structure, and word order. United Kingdom: Routledge.

Newport, E., \& Aslin, R. (2004). Learning at a distance I. Statistical learning of nonadjacent dependencies. Cognitive Psychology, 48(2), 127-162.

Obler, L.K. (2012). Conference interpeting as extreme language use. International Journal of Bilingualism, 16(2), 177-182.

Oehrle, R. (1976). The Grammatical Status of the English Dative Alternation.PhD Thesis, MIT. Cambridge.

Olson, L., \& Samuels, S.J. (1973). The relationship between age and accuracy of foreign language pronunciation. Journal of Educational Research, 66, 263-267. 
Opitz, B., \& Degner, J. (2012). Emotionality in a second language: It's a matter of time. Neuropsychologia, 50, 1961-1967

Padilla, P., Bajo, M., Cañas, J., \& Padilla, F. (1995). Cognitive processes of memory in simultaneous interpretation. In J. Tommola (Ed.), Topics in interpreting research, 61-72. Turku: University of Turku.

Papadopoulou, D., \& Clahsen, H. (2003). Parsing strategies in 11 and 12 sentence processing. Studies in Second Language Acquisition, 25.

Paradis, M. (1984). Aphasie et traduction. Meta: Journal Des Traducteurs, 29(1).

Paradis, M. (1994). Toward a Neurolinguistic Theory of Simultaneous Translation: The Framework. International Journal of Psycholinguistics, 10 (3).

Peal, E., \& Lambert, W. E. (1962). The relation of bilingualism to intelligence. Psychological Monographs, 76, 1-23.

Pickering, M., \& Branigan, H. (1998). The representation of verbs: Evidence from syntactic priming in language production. Journal of Memory and Language, 39, $633-651$. 
Pickering, M., \& Branigan, H. (1999). Syntactic priming in language production. Trends in Cognitive Sciences, 3, 136-141.

Pickering, M., \& Garrod, S. (2004). Toward a mechanistic psychology of dialogue. Behavioral and Brain Sciences, 27, 169-225.

Pickering, M., \& Garrod, S. (2007). Do people use language production to make predictions during comprehension?. Trends in Cognitive Sciences, 11, 105-110.

Pickering, M., \& Ferreira, V. (2008). Structural priming: A critical review. Psychological Bulletin, 134(3), 427-459.

Pinker, S. (1991). Learnability and Cognition: The Acquisition of Argument Structure. United States: The MIT Press.

Prinz, J. J. (2006). Is the Mind Really Modular? In R. Stainton, Contemporary debates in cognitive science. United Kingdom: Wiley, John \& Sons, Incorporated.

Pylkkänen, L. (2002). Introducing Arguments. PhD Thesis. MIT.

Proverbio, A. M., Leoni, G., \& Zani, A. (2004). Language switching mechanisms in simultaneous interpreters: an ERP study. Neuropsychologia, 42, 1636-1656. 
Ruiz, C., Paredes, N., Macizo, P., \& Bajo, M. T. (2008). Activation of lexical and syntactic target language properties in translation. Acta Psychologica, 128(3), $490-500$.

Rinne, J.O., Tommola, J., Laine, M., Krause, B.J., Schmidt, D., Kaasinen,V.,...Sunnari, M. (2000). The translating brain: cerebral activation patterns during simultaneous interpreting. Neuroscience Letters 294, 85-88.

Sabourin, L., Brien, C., \& Burkholder, M. (2013). The effect of age of L2 acquisition on the organization of the bilingual lexicon: Evidence from masked priming. Bilingualism: Language and Cognition, 17(03), 542-555.

Sabourin, L., \& Vīnerte, S. (2014). The bilingual advantage in the Stroop task: simultaneous vs. early bilinguals. Bilingualism: Language and Cognition, 1-6.

Scholz, B. C. (2006). Irrational Nativist Exuberance. In G. K. Pullum (Ed.), R. Stainton, Contemporary debates in cognitive science. United Kingdom: Wiley, John \& Sons, Incorporated.

Seeber, K.G., \& Kerzel, D. (2011). Cognitive load in simultaneous interpreting: Model meets data. International Journal of Bilingualism, 16(2), 228-242. 
Seleskovitch, D. (1978). Language and Cognition. Language Interpretation and Communication, 333-341.

Signorelli, T.M., Haarmann, H.J., \& Obler, L.K. (2011). Working memory in simultaneous interpreters: Effects of task and age. International Journal of Bilingualism, 16(2), 198-212.

Skinner, B. (1991). Verbal Behavior (B.F. Skinner Reprint Series) (B.F. Skinner Reprint Series) (B.F. Skinner Reprint Series) (B.F. Skinner Reprint Series). United States: Copley Publishing Group.

Taylan, E. E. (1984). The function of word order in Turkish grammar. United States: University of California Press.

Tóth, Z. (2006). First-year English majors' perceptions of the effects of foreign language anxiety on their oral performance. In M. Nikolov \& J. Horvath (Eds.), UPRT 2006: Emprical studies in English applied linguistics, 25-37. Pecs: LinguaFranca.

Traxler, M. (2002). Plausibility and subcategorization preference in children's processing of temporarily ambiguous sentences: Evidence from self-paced reading. The Quarterly Journal of Experimental Psychology Section A, 55(1), 75-96. 
Trueswell, J., Sekerina, I., Hill, N., \& Logrip, M. (1999). The kindergarten-path effect: studying on-line sentence processing in young children. Cognition, 73(2), 89-134.

Tzou, Y., Eslami, Z.R., Chen, H., \& Vaid, J. (2011). Effect of language proficiency and degree of formal training in simultaneous interpreting on working memory and interpreting perfomace: Evidence from Mandarin-English speakers. International Journal of Bilingualism, 16 (2,) 213-227.

Ullman, T. (2001). The neural basis of lexicon and grammar in first and second language: The declarative/procedural model. Bilingualism: Language and Cognition, 4, $105-122$.

Verhoeven, E. (2014). Thematic prominence and animacy asymmetries. Evidence from a cross-linguistic production study. Lingua, 143, 129-161.

Volterra, V., \& Taeschner, T. (1978). The acquisition and development of language by bilingual children. Journal of Child Language, 5.

Weinreich, U. (1953). Languages in Contact. The Hague: Mouton. 
Yip, V., \& Clahsen, H. (1995). Interlanguage and Learnability: From Chinese to English (Language Acquistion \& Language Disorders Vol. 11). (W. Rutherford, Ed.). Philadelphia: Benjamins (John) North America Inc.,US.

Yip, V., \& Matthews, S. (2007). The bilingual child: early development and language contact. United Kingdom: Cambridge University Press. 